\title{
Sensing, transport and other potential biomedical applications of pseudopeptides
}

\author{
Enrico Faggi ${ }^{\mathrm{a}}$, Santiago V. Luis ${ }^{\mathrm{b}}$ and Ignacio Alfonso ${ }^{* \mathrm{a}}$ \\ ${ }^{a}$ Department of Biological Chemistry and Molecular Modelling, Institute of Advanced Chemistry of Catalonia, \\ Consejo Superior de Investigaciones Científicas, Barcelona, Spain; ${ }^{b}$ Department of Inorganic and Organic \\ Chemistry, Universitat Jaume I, Castellón, Spain
}

\begin{abstract}
Pseudopeptides are privileged synthetic molecules built from the designed combination of peptidelike and abiotic artificial moieties. Consequently, they are benefited from the advantages of both families of chemical structures: modular synthesis, chemical and functional diversity, tailored three-dimensional structure, usually high stability in biological media and low non-specific toxicity. Accordingly, in the last years, these compounds have been used for different biomedical applications, ranging from bio-sensing, ion transport, the molecular recognition of biologically relevant species, drug delivery or gene transfection. This review highlights a selection of the most remarkable and recent advances in this field.
\end{abstract}

Keywords: pseudopeptides; sensing; transport; cation coordination; anion coordination; gene delivery

\section{INTRODUCTION}

Pseudopeptidic molecules are chemical structures constructed by the combination of peptide-like moieties and non-natural artificial moieties.[1-3] A general representation of this type of structures is depicted in Figure 1. The peptidic part of these molecules can be made of naturally occurring or non-natural amino acids connected through amide bonds. One big advantage is that this design allows a very broad structural and functional diversity. On one hand, they can include very different functional groups and moieties, as those present in the amino acid family. On the other hand, and thanks to the non-natural parts, it is possible the tailor-made inclusion of artificial groups or constraints to implement desired functions (signaling, catalysis, transport) or physico-chemical properties (conformational preferences, hydrophobicity, water solubility, self-assembly, etc.). Thus, these molecules are highly modular and versatile. Besides, their design can be benefited by a high degree of bioinspiration and mimicry of the Natural World. For instance, the peptidic moiety in Figure 1 can form part of a natural peptide fragment with a given biological function. Moreover, the peptidic moiety has interesting properties for the biological applications of the pseudopeptides. In principle, they usually show low nonspecific toxicity in biological studies. Additionally, the corresponding preparation can be accomplished by wellestablished synthetic methods, either by solution or solidphase peptide synthesis protocols. This is very interesting for the combinatorial generation of libraries for the screening of different pseudopeptides against a given biomolecular target. Regarding those applications, the non-peptidic fragments often increase the stability of the molecules in biological media, since they protect the molecules from the hydrolytic action of proteases.[4] Considering that hydrolysis of peptides by natural enzymes is a very important drawback of the use peptides in biomedicine, the enhanced stability of pseudopeptides makes them especially attractive in this specific area of research. Under the wide definition of pseudopeptides here presented, we have selected representative examples in the field, prioritizing those where the biological application (or potential biomedical usage) has been described or foreseen. Some of the selected examples were originally classified as peptides, bearing a modified or non-natural amino acid. We do not intend to re-define the molecules prepared and studied by others, but our intention with this review has been to collect representative examples where the peptidic and the non-peptidic parts of the chemical structures play a fundamental role in the described properties and biological applications. In addition to that, this review has been written in a critical manner, trying to highlight the advantages and disadvantages of the molecular systems, in terms of the intended biomedical applications, and does not intend to cover the field in an exhaustive way. The literature has been covered since 1993 to the beginning of 2017 .

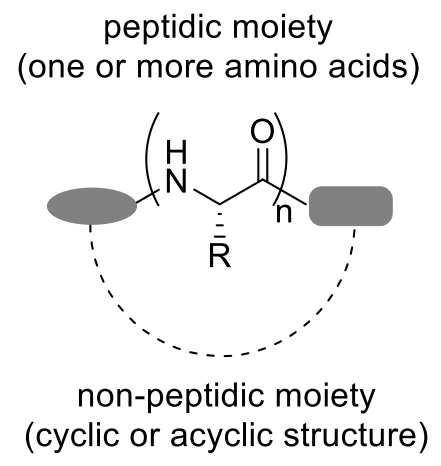

Figure 1. General structure of a pseudopeptide.

2. PSEUDOPEPTIDES WITH SENSING ABILITY

\subsection{Sensing of intracellular $\mathrm{pH}$}


The control of intracellular $\mathrm{pH}$ is essential for many cellular events, including cell growth and apoptosis.[5] Therefore, the exploring cellular functions and the understanding of physiological and pathological processes inside living cells can be done by monitoring $\mathrm{pH}$ changes. Intracellular $\mathrm{pH}$ in the cytosol is normally in the range of 6.8 and 7.4, while between 4.5 and 6.0 in some acidic organelles like lysosomes, and around 8-8.5 in mithocondria.[6] Consequently, $\mathrm{pH}$ indicators for environments with nearneutral, slightly acidic and slightly basic pHs have been developed, being some of them commercially available. Fluorescent probes can signal the intracellular $\mathrm{pH}$ by variation of the fluorescence intensity, by a spectral shift in the emission or by a change in the ratio of the intensities of two emission bands (ratiometric).[7] Among the many reported sensors are small molecules containing the "fluorophore- $\mathrm{CH}_{2}-$ amine" moiety. In these systems, the $\mathrm{pH}$-induced fluorescence changes can be rationalized according to the photoinduced electron-transfer (PET) scheme:[8] under basic conditions the amino groups are not protonated, and their lone pairs are responsible for the PET process that leads to fluorescence quenching. In acidic media amines are protonated, thus preventing PET from occurring, and hence emission from the fluorophore takes place. Some pseudopeptides are amidoamines, therefore when they are conjugated with fluorophores, they can afford $\mathrm{pH}$ probes based on the PET paradigm. Thanks to their modular and facile synthesis, they hold the potential for precise control (and prediction) of the $\mathrm{pKa}$ value of the probe by adjusting the appropriate elements in the molecular architecture.

Luis and coworkers reported on a family of fluorescent macrocyclic probes that consist of an anthracene fluorophore linked to different pseudopeptidic moieties derived from valine and phenylglycine.[9, 10] Compounds 1-7 are macrocycles of different chain length, 8-9 are open-chain probes with two pseudopeptidic arms, and 10-12 are openchain probes with only one pseudopeptidic arm (Figure 2).

According to the PET mechanism, these probes are highly emissive at acidic pHs, while their emission is quenched at neutral or alkaline $\mathrm{pHs}$. Accurate titration curves (emission at $430 \mathrm{~nm} v s . \mathrm{pH}$ ) showed how the subtle structural variations considered produced a smooth shift in the $\mathrm{pKa}$ values, which varied from 4.5 to 6.5 , thus covering a broad and biochemically important $\mathrm{pH}$ range, and showing the possibility to finely tune the $\mathrm{pKa}$ of the fluorescent sensors by the appropriate selection of the synthetic molecular moieties.

In particular, the macrocyclic compounds 1-6 derived from valine have $\mathrm{pKa}$ values in the acidic region (4.6-5.4). Pseudopeptidic compounds $\mathbf{1 0}$ and 11, monosubstituted in the anthracenic ring and derived from valine too, are characterized by values of $\mathrm{p} K$ a above 6 . The lower $\mathrm{p} K$ a values for the diamines can be explained due to the occurrence of a first protonation of the first nitrogen atom, which makes more difficult the protonation of the second amine (which is the one observable by fluorescence change) due to electrostatic repulsion. This sequential protonation is not possible in the case of the monoamine probes and the observed $\mathrm{pKa}$ is around one unit higher. Moreover, the steric hindrance of the bulky anthracenic moiety should also contribute to the relatively low basicity of this type of sensors, which makes them useful for monitoring acidic $\mathrm{pH}$ values.

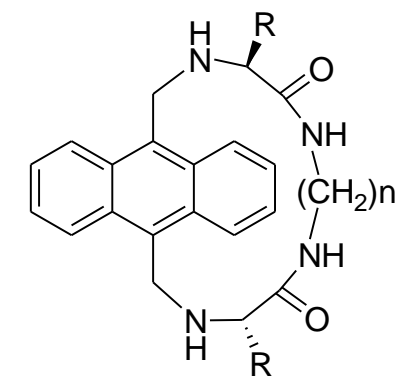

$$
\begin{aligned}
& \text { 1: } \mathrm{R}=\mathrm{CH}\left(\mathrm{CH}_{3}\right)_{2}, \mathrm{n}=2 \\
& \text { 2: } \mathrm{R}=\mathrm{CH}\left(\mathrm{CH}_{3}\right)_{2}, \mathrm{n}=3 \\
& \text { 3: } \mathrm{R}=\mathrm{CH}\left(\mathrm{CH}_{3}\right)_{2}, \mathrm{n}=4 \\
& \text { 4: } \mathrm{R}=\mathrm{CH}\left(\mathrm{CH}_{3}\right)_{2}, \mathrm{n}=5 \\
& \text { 5: } \mathrm{R}=\mathrm{CH}\left(\mathrm{CH}_{3}\right)_{2}, \mathrm{n}=6 \\
& \text { 6: } \mathrm{R}=\mathrm{CH}\left(\mathrm{CH}_{3}\right)_{2}, \mathrm{n}=8 \\
& \text { 7: } \mathrm{R}=\mathrm{Ph}, \mathrm{n}=3
\end{aligned}
$$
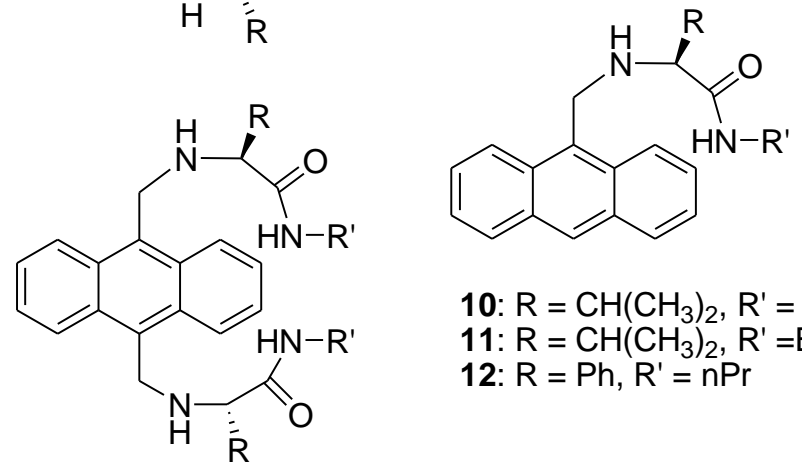

10: $\mathrm{R}=\mathrm{CH}\left(\mathrm{CH}_{3}\right)_{2}, \mathrm{R}^{\prime}=\mathrm{nPr}$

11: $\mathrm{R}=\mathrm{CH}\left(\mathrm{CH}_{3}\right)_{2}, \mathrm{R}^{\prime}=\mathrm{Bn}$

12: $\mathrm{R}=\mathrm{Ph}, \mathrm{R}^{\prime}=\mathrm{nPr}$
8: $\mathrm{R}=\mathrm{CH}\left(\mathrm{CH}_{3}\right)_{2}, \mathrm{R}^{\prime}=\mathrm{nPr}$
9: $\mathrm{R}=\mathrm{Ph}, \mathrm{R}^{\prime}=\mathrm{nPr}$

Figure 2. Chemical structures of probes 1-12.

The fluorescence response was selective towards $\mathrm{pH}$, with negligible effects caused by excess of $\mathrm{Zn}$ (II) and $\mathrm{Cu}(\mathrm{II})$ ions, which in principle could affect the fluorescence properties by coordination to the amidoamine moieties. Compounds 1-12 showed excellent cellular uptake, thanks to an intermediate polarity (calculated $\log \mathrm{P}$ in the 4.7-6.4 range). Probe 2 was investigated as a fluorescent probe in cultured cells and was compared to DND-189 (a commercially available probe, based on the benzimidazo[2,1-a]benz[d,e]isoquinolion-7-one fluorophore, and known to enter the cells and localize into the acidic organelles). The pseudopeptidic probe predominantly co-localized with DND-189, which indicates that the probe is taken up by the cells and that it localizes within acidic organelles. The different excitation and emission wavelengths of $2(\lambda \mathrm{ex}=377 \mathrm{~nm} ; \lambda \mathrm{em}=430 \mathrm{~nm})$, as compared to those of the commercial probe $(\lambda \mathrm{ex}=443 \mathrm{~nm} ; \lambda \mathrm{em}=505 \mathrm{~nm})$, allowed simultaneous visualization of both probes from the same intracellular compartment. Interestingly, the fluorescence intensity of 2 appears to match that of DND- 189: areas of low and high fluorescence of the probe match those of DND-189, which indicates that probe 2 can distinguish between different $\mathrm{pH}$ values in the cell in a manner similar to the commercial probe.

The ratio of emission intensities between on and off states was also investigated. This ratio reflects to some extent the visual contrast that potentially could be achieved in a bioimaging application. The reported PET probes showed a high contrast with high values for the ON state $(\varphi \max =0.7-$ $0.9)$ and very low values for the OFF state $(\varphi \min =0.007-$ 
0.149), which leads to $\varphi \max / \varphi \min$ ratios of up to 106 (for compound 9).

Moreover, to test the potential biomedical utility of these acidity sensors, the phagocytosis process of a culture of fluorescent bacteria by human leukocytes was followed. The intracellular acidity was taken as a reporter parameter, measured by probe $\mathbf{2}$ and using flow cytometry as the bioanalytical tool.

In conclusion, compounds 1-12 are a family of convenient fluorescent indicators for intracellular $\mathrm{pH}$, offering high cellular uptake, high $\varphi \max / \varphi$ min ratios, significant Stoke shift $(57 \mathrm{~nm})$ and closely spaced $\mathrm{p} K$ as in the 4.6-6.5 $\mathrm{pH}$ range. They can be successfully used for the visualization of acidic organelles. On the other hand, their major disadvantage is the need to excite at $370 \mathrm{~nm}$ with a UV-A laser, a feature due to the presence of the anthracene chromophore. Furthermore, in a recent study, collisional and static quenching of some of these probes has been observed in the presence of electronrich, aromatic amino acids, such as Trp and Tyr.[11] However, given the typical concentrations of the probes and the amino acids under normal conditions and the very low association constants detected (9-24 $\mathrm{M}^{-1}$ range) for the probe-amino acid complexes, this fact does not hamper the use of 1-12 for $\mathrm{pH}$ sensing.

Probably one of the most widely studied fluorophore is pyrene, which displays the property of dual monomer/excimer fluorescence. This specific feature has been exploited for the detection of several analytes such as protons, but scarcely applied to intracellular $\mathrm{pH}$ sensing.

In this regard, the pseudopeptide $\mathbf{1 3}$ is formed by a central $\mathrm{C}_{2}$ symmetric bis(aminoamide) moiety derived from the amino acid serine and two terminal pyrene groups (Figure 3).[12] The final compound displays an intermediate polarity, as required for cell permeability, which was obtained by balancing the hydrophobic character of the pyrene rings and highly hydrophilic serine residues, rendering an overall calculated $\log P=6.2$. Finally, the short ethylenic spacer was implemented to ease the stacking of the pyrene moieties. In aqueous media, both monomer and excimer emissions are observed throughout the studied $\mathrm{pH}$ values, their intensity being $\mathrm{pH}$-dependent. The excimer emission at $490 \mathrm{~nm}$ is of low intensity at basic $\mathrm{pH}$ and increases (about 6-fold) from $\mathrm{pH}$ 6.6 to 2.9. In particular, in the $6.05-4.25 \mathrm{pH}$ range, this increase is linearly $4.7-$ fold $(\mathrm{pKa}=5.0)$. The careful analysis of the absorption, emission and proton NMR spectra of $\mathbf{1 3}$ at different $\mathrm{pH}$ values allowed elaborating a model for the mechanism of sensing. At neutral or basic $\mathrm{pH} \mathbf{1 3}$ nonspecifically aggregates, affording large pyrene clusters with low emission efficiency. At acidic $\mathrm{pH}$ a folded conformation with intramolecular stacking of the pyrene rings affords isolated stacked dimers with high emission efficiency. Therefore, the pseudopeptidic spacer plays a fundamental role in the emission properties of the probe, by controlling the $\mathrm{pH}$ dependent self-assembly and conformation of the species in aqueous media. A plausible conformer (by molecular mechanics calculations) suggested an intramolecular H-bond between a carbonyl amide and an ammonium group. The final consequence is an emission $v s$. $\mathrm{pH}$ curve that is opposite to that normally found for pyrene-containing polyamines or polyamidoamines.

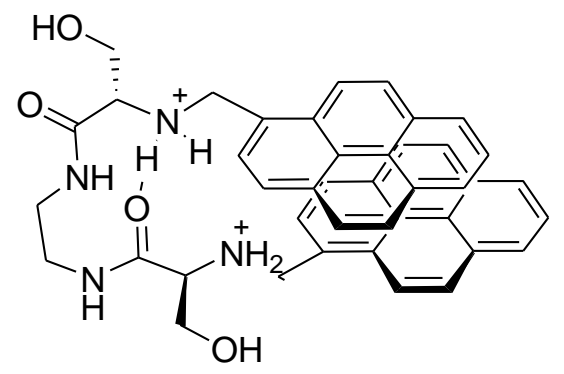

13

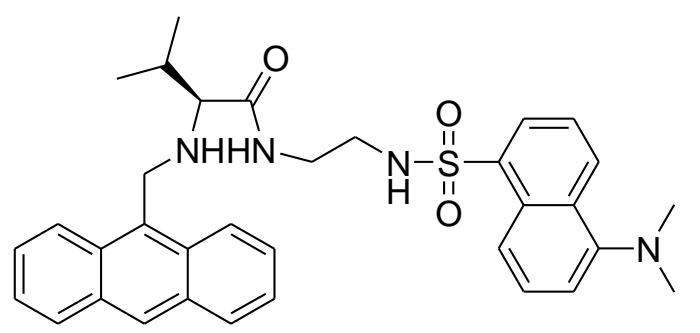

14

Figure 3. Structures of probe $\mathbf{1 3}$ in its protonated folded form (above) and probe 14 (below).

The pH-dependent fluorescence emission of $\mathbf{1 3}$ is not affected by potentially competing species like transition metal cations; this feature makes $\mathbf{1 3}$ suitable for intracellular $\mathrm{pH}$ sensing in the acidic range. In fact, a fluorescence microscopy study revealed that $\mathbf{1 3}$ allows the visualization of acidic organelles in human lung adenocarcinoma A549 cells, as well as their $\mathrm{pH}$ changes over time, studied by addition of chloroquine. The advantages of this probe include its easy and modular synthesis, low cytotoxicity, good photostability, fast optical response and especially a large Stokes shift (ca. 145 $\mathrm{nm})$. The latter property is of great interest for biological applications since excitation and emission are separated to avoid self-absorption phenomena or autofluorescence. On the other hand, 13 requires excitation in the UV range (at $345 \mathrm{~nm}$ ), and suffers from a relatively low $\varphi_{\max } / \varphi_{\min }$ ratio.

While the majority of fluorescent probes for intracellular $\mathrm{pH}$ are based on simple PET mechanism and signal the intracellular $\mathrm{pH}$ by variation of the fluorescence intensity (turn-on sensors), probes that achieve the same result by a change in the intensity of two (or more) emission bands (ratiometric sensors) have recently attracted much interest. This is because ratiometric sensors offer increased sensitivity and improved quantification of analytes thanks to an effective internal referencing. Ratiometric sensors are more reliable, as they do not suffer interference from a variety of analyteindependent factors, such as instrumental parameters, the microenvironment around the probe molecule, the local concentration of the probe molecule, photobleaching, etc.

Compound $\mathbf{1 4}$ is a bichromophoric $\mathrm{pH}$ probe that contains two fluorophores (anthracene and dansyl) linked by a flexible pseudopeptidic spacer containing the amino acid valine (Figure 3).[13]

The emission of $\mathbf{1 4}$ in the neutral-basic $\mathrm{pH}$ region is that arising from the dansyl chromophore (a strong and broad band centered at $490 \mathrm{~nm}$ ), whereas in the acidic $\mathrm{pH}$ region, the 
prevalent emission is due to the anthracene chromophore (centered at $420 \mathrm{~nm}$ ). These results conclude that compound 14 is a dual fluorescence $\mathrm{pH}$ probe which is able to emit in two different spectral regions as a function of the $\mathrm{pH}$ of the medium thus enabling the possibility of ratiometric measurements. At the mechanistic level, the results are described as a combination of electronic energy transfer (EET) from the excited anthracene moiety to the dansyl fragment along with a competitive PET process.

The titration curve of compound $\mathbf{1 4}$ representing the ratio of intensities at $490 \mathrm{~nm}$ and $420 \mathrm{~nm}$ vs. $\mathrm{pH}$ afforded an apparent $\mathrm{pKa}$ of 5.6 and a quasi-linear tenfold increase between $\mathrm{pH} 5.5$ and 8.5 , offering the possibility of quantifying the $\mathrm{pH}$ of the media in a region close to neutrality. Additionally, the bichromophoric compound 14 displays a large Stokes shift (115 nm, referred to the dansyl emission).

The appropriate selection of the emitting moieties is the key factor for the success of the sensor: other assayed combinations, such as anthracene with either pyrene or 4nitrobenzo-2-oxa-1,3-diazole (NBD) failed to afford $\mathrm{pH}$ probes exhibiting this behavior.

Due to its $\mathrm{pKa}=5.6$, compound $\mathbf{1 4}$ was used to perform intracellular measurements within RAW 264.7 mouse macrophage cells. The confocal fluorescence images and the fluorescence emission spectra of $\mathbf{1 4}$ from within the RAW 264.7 cells confirmed the internalization of the probe by the cells. Co-localization experiments were performed using LysoTracker Red DND-99 as a marker of acidic organelles.

Compound 14 was distributed around the cell with partial localization in the organelles marked by the DND-99, probably marking early and late endosomes within the treated RAW 264.7 cells.

$\mathrm{Wu}$, Tian, and co-workers reported on a bis-spiropyran functionalized pseudopeptide, 15, as a sensor for real-time lysosomal tracking (Figure 4).[14] Spiropyran moieties undergo reversible structural isomerization from a colorless spiro-form (spiropyran, SP) to a colored open-form (merocyanine, Mc) by UV/Vis light illumination and/or $\mathrm{pH}$ changes. The peptidic part of $\mathbf{1 5}$ contains positively charged lysine residues to favor the interaction with negatively charged lysosomal membranes. In water, below $\mathrm{pH} 2,15$ shows an absorption band at $410 \mathrm{~nm}$ (attributed to the protonated merocyanine units, $\mathrm{McH}^{+}$) and a relatively weak fluorescence emission at $623 \mathrm{~nm}$. Increasing the $\mathrm{pH}$ value up to 6 gives rise to higher fluorescence intensity (approximately a 3-fold increase), while the absorption band exhibits a bathochromic shift to $514 \mathrm{~nm}$, a representative absorption of neutral merocyanine $(\mathrm{Mc})$. Further increase of the $\mathrm{pH}$ from 6 to 10 provokes a decrease of the fluorescence intensity and the ring-closing reaction leading to spiropyran (Sp). The ringclosing reaction can be performed also by Vis-light irradiation, at any $\mathrm{pH}$. When left in the darkness, the spiropyran units isomerize to merocyanine or protonated merocyanine moieties, depending on $\mathrm{pH}$. This feature makes 15 a potential reversible lysosomal tracker.

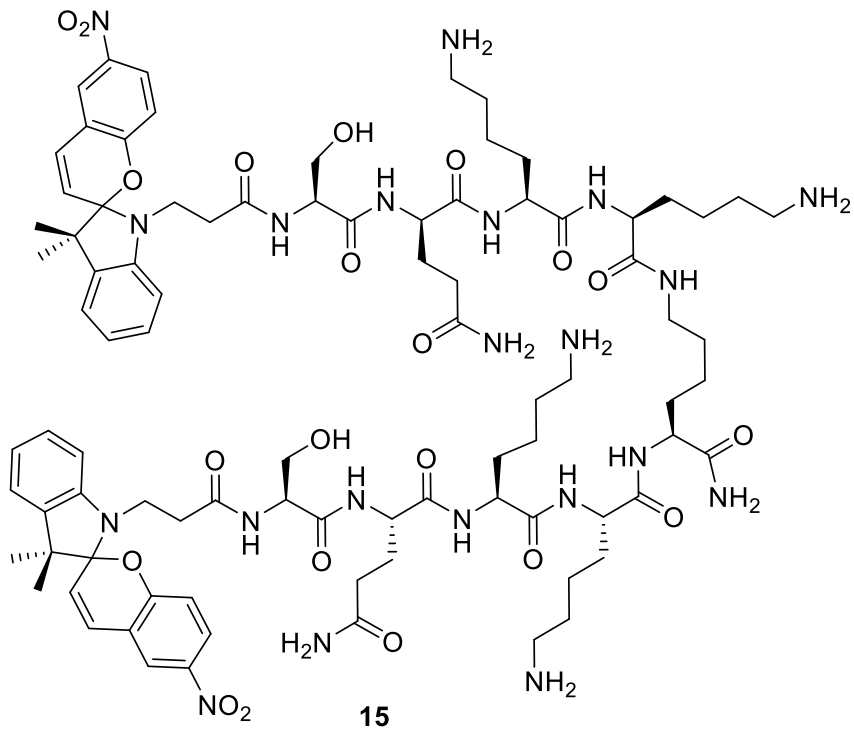

Figure 4. Structure of the pseudopeptidic probe $\mathbf{1 5}$.

When incubating live A549 cells with 15, an intense red luminescence was detected in the cytoplasm. The red signals came from the acidic organelles (the intracellular lysosomes), as confirmed by a colocalization experiment of $\mathbf{1 5}$ with LysoTracker Green DND-26.

Afterwards, $\mathbf{1 5}$ was tested as a switchable sensor to track lysosomes in A549 cells. Firstly, a time course ring-opening process of $\mathbf{1 5}$ was conducted within cells. After treatment with visible light for $c a .5 \mathrm{~min}$, no fluorescence was detected by laser confocal microscopy, which suggested that $\mathbf{1 5}$ was present in the ring-closed form. The A549 cells became increasingly brighter (red fluorescence) as the time elapsed, and after the cells being kept in darkness for $c a .15 \mathrm{~min}$, the red fluorescence of $\mathbf{1 5}$ revived. Irradiation/darkness cycles were repeated successively: the reversible off-on fluorescence imaging of targeted cells could be repeated at least eight times within cells with little photobleaching. As a result, the time-lapse ring opening process made $\mathbf{1 5}$ a potential candidate for real-time dynamic monitoring of lysosome, also taking into account its low cytotoxicity.

In spite of the low ratio between the fluorescence intensities of the ON/OFF states, the other features of $\mathbf{1 5}$ described here suggest the utility of this pseudopeptidic probe in live cell imaging applications for lysosomal tracking.

\subsection{Sensing of small organic metabolites}

Boronic acids form cyclic esters with 1,2- and 1,3 diols; for this reason, several receptors for monosaccharides based on boronic acids have been developed. The research group of Kubik reported on the macrocyclic tetra(pseudo)peptide 16, which contains alternating L-proline and 3-aminobenzoic acid residues and is functionalized with two boronic acid moieties (Figure 5).[15] In this receptor, the pseudopeptidic ring functions as a molecular hinge that allows the distance and the orientation of the binding sites to adapt to the size of a bound substrate. Coordination abilities of $\mathbf{1 6}$ were tested firstly by ESI mass spectrometry, towards D-glucose, L-glucose, D- 
galactose, D-mannose, D-allose, D-fructose, D-ribose, and Dxylose. Significant amounts of the 1:1 complexes could only be observed for D-glucose and L-glucose. This selectivity should depend mainly on the reciprocal arrangement of the binding sites, which, in turn, is controlled by the structure of the receptor.

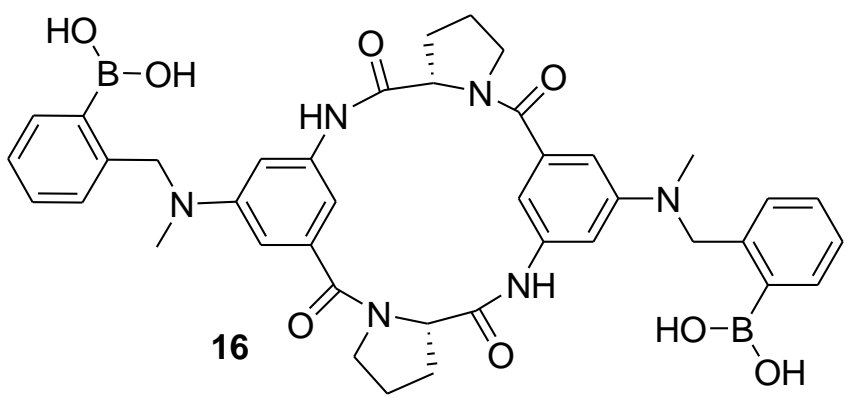

Figure 5. Structure of the tetra(pseudo)peptide 16; a sensor for glucose.

The binding was also studied by NMR spectroscopy. Free 16 exhibits a ${ }^{1} \mathrm{H}$ NMR spectrum with broad peaks, probably due to conformational interconversion and/or intra- or intermolecular interactions between the boronic acid groups. Upon addition of D-glucose, a new set of much sharper signals appears, pointing out the formation of a structurally defined complex, which is in slow equilibrium with free $\mathbf{1 6}$ in the NMR timescale. Finally, the complex stability was determined by fluorescence titrations. In $1: 1$ water : methanol (pH 11.7) $\mathbf{1 6}$ displays a strong emission band centered around $480 \mathrm{~nm}$. Addition of (D/L)-glucose to the solution causes the fluorescence intensity of this band to decrease. The comparison of the stability constants $\left(2.7 \cdot 10^{5} \mathrm{M}^{-1}\right.$ for the 16. D-glucose complex; $1.2 \cdot 10^{5} \mathrm{M}^{-1}$ for the complex with Lglucose), shows that $\mathbf{1 6}$ binds D-glucose $c a$. two times better than L-glucose.

The observed quenching could in principle allow the use of 16 as a chemosensor for glucose, but it has to be noted that the decrease of emission intensity is only about $40 \%$ (in presence of 10 equivalents of glucose) and that the equilibrium is reached after 90 minutes. Additionally, the binding only takes place at very high $\mathrm{pH}(\approx 12)$ and this further limits the use of this compound in practical applications.

Among the analytes of great interest in biomedicine lies the $\alpha$-amino acid family. While the amino acids with a polar and reactive lateral chain are somewhat easier to detect, those with apolar and unreactive side chain (like Ala, Val, Phe, Leu, etc.) represent a more difficult target for which practical chemosensors are still awaited. Luis et al. reported on the supramolecular analytical behavior of pseudopeptidic macrocyclic or open chain fluorescent receptors, based on the naphthalene chromophore (17 and 18, Figure 6).[16] The ability of these receptors to recognize amino acids (as Zprotected derivatives) has been evaluated in dichloromethane. The emission of naphthalene derivatives takes place typically at $c a .340 \mathrm{~nm}$. However, these compounds present a new emission band at $390 \mathrm{~nm}$. The intensity of this band depends on the structure of the compound and has been identified as an emissive exciplex, i.e. an internal complex formed between the excited naphthalene chromophore and the secondary amines of the macrocyclic ring. When phenylalanine is added to the receptors, the exciplex emission decreases, while the native naphthalene emission increases. 17 and 18 bind preferentially to phenylalanine (Phe) with respect to aliphatic amino acids (Ala, Val) by a factor of 3-4. Free $\mathbf{1 7}$ and $\mathbf{1 8}$ display high exciplex emissions, with dramatic fluorescence changes upon binding of phenylalanine (fluorescence quenching at $390 \mathrm{~nm}$ and fluorescence enhancement at 340 $\mathrm{nm})$.

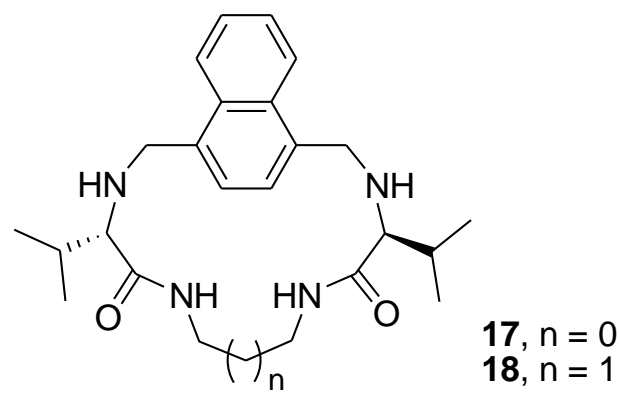

Figure 6. Structure of the fluorescent probes $\mathbf{1 7}$ and $\mathbf{1 8}$.

This feature makes the macrocycles $\mathbf{1 7}$ and $\mathbf{1 8}$ potentially useful as fluorescent ratiometric sensors for Phe, therefore they have been assayed as analytical tools for the identification of model samples enriched with Phe (mimicking the concentrations found in the pathology phenylketonuria), and deprived of such amino acid (like in the maple syrup urine disease). $\mathbf{1 7}$ and $\mathbf{1 8}$ were able to discriminate such samples from normal ones, providing a positive or negative response (stronger or weaker naphtalene emission, with respect to normal samples). This result is the first step towards the development of Phe sensors useful for the analysis of aminoacidemias. In fact, the described sensors are not ready for practical purposes, being limited to dichloromethane environment and the use of Z-protected amino acids.

\subsection{Sensing of biologically relevant anions}

The Jolliffe research group described a family of bis(Zn(II)-Dpa) functionalized cyclic pseudopeptides. The macrocycles are composed of alternating natural amino acids (Leu, Ala, Phe, Orn) and oxazole rings, which can be considered as amide bond surrogates. The number of the ring members vary from six to eight, and the ornithine side chains are functionalized with dipicolylamino (Dpa) arms and finally complexed with Zn(II). Every macrocycle bears two Zn-Dpa groups, arranged in a $\mathrm{C}_{2}$-symmetrical or unsymmetrical fashion (19-24Zn 2 , Figure 7). These $\mathrm{Zn}$-Dpa groups are able to establish strong bonds with several anions, and therefore the anion binding ability of the pseudopeptidic macrocycles has been investigated using displacement assays with a fluorescent coumarin indicator in water.[17]

Titrations of equimolar mixtures of indicator and pseudopeptide with di- and triphosphate anions (PPi, ATP and ADP) resulted in significant increases in fluorescence 
intensity indicating displacement of the indicator. On the other hand, monophosphate anions (AMP, cAMP, phosphoserine, phosphotyrosine, hydrogenphosphate) and polycarboxylates (acetylglutamate and Ac-Glu-Gly-Glu) did not induce the displacement. The receptors display differences in binding affinity and selectivity. The binding data of the series $19-\mathbf{2 1} \cdot \mathbf{Z n}_{2}$ indicates that while the hydrophobic cleft provided by the Leu side chains of $\mathbf{2 0} \cdot \mathbf{Z} \mathbf{n}_{2}$ results in similar affinity for all three anions, the smaller Ala substituents of 19. $\mathbf{Z n}_{2}$ provide some selectivity for PPi over ATP and ADP. In contrast, for $\mathbf{2 1} \cdot \mathbf{Z n}_{2}$, bearing Phe side chains, the binding order is $\mathrm{ATP} \approx \mathrm{PPi}>\mathrm{ADP}$. The presence of two close $\mathrm{Zn}$ (II)Dpa sites increase the selectivity for PPi over ATP and ADP in both the Phe and Leu series. Notably, the affinity of $\mathbf{2 2} \cdot \mathbf{Z n}_{2}$ (with proximal $\mathrm{Zn}(\mathrm{II})-\mathrm{Dpa}$ sites) for PPi is more than one order of magnitude higher than that of $\mathbf{2 0} \cdot \mathbf{Z} \mathbf{n}_{2}$ (with distal $\mathrm{Zn}$ (II)-Dpa groups). Also changing the size of the cyclic peptide scaffold while maintaining the same distance between the binding sites had a significant effect on binding affinity, with the smaller $\mathbf{2 4} \cdot \mathbf{Z} \mathbf{n}_{\mathbf{2}}$ binding PPi one order of magnitude stronger than the larger $\mathbf{2 2} \cdot \mathbf{Z n}_{2}$ and with increased selectivity over both ATP and ADP.

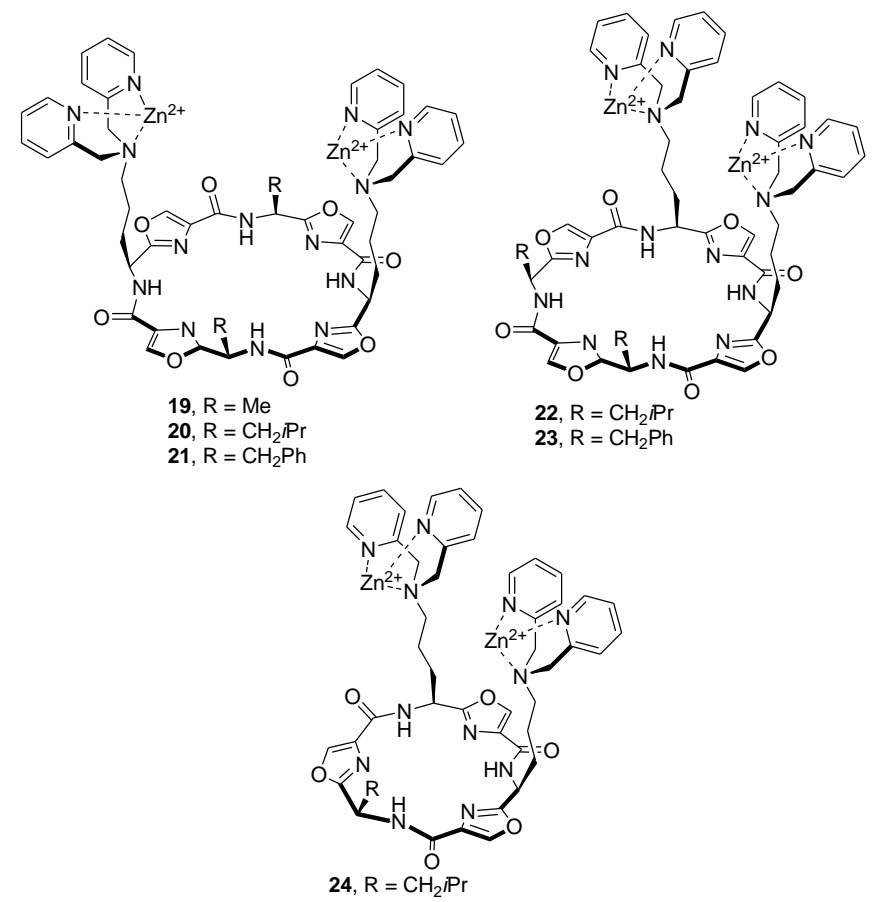

Figure 7. Structure of sensors 19-24.

In a saline solution, all receptors retain their selectivity for di- and triphosphate anions over monophosphate derivatives, although a slightly lower affinity was observed. An enhanced selectivity was observed in Krebs buffer, a complex medium that contains high concentrations of phosphate anions and $\mathrm{Ca}^{2+}$ and $\mathrm{Mg}^{2+}$ ions, both of which are known to strongly bind to PPi, ATP, and ADP. Ensembles $19-24 \cdot \mathbf{Z n}_{2}$ had a remarkable ability to discriminate between $\mathrm{PPi}$ and ATP/ADP: only PPi was able to completely displace the indicator from the receptor, while ATP and ADP gave minor fluorescence changes.
This improved selectivity enables low micromolar concentrations of PPi to be detected in the presence of excess ATP, which could be useful in monitoring enzymatic reactions in which PPi is generated.

Shortly after, the same group expanded this research line, reporting on a library of anion receptors comprising cyclic pseudopeptide scaffolds bearing two (Zn(II)-DPA) anion binding sites $\left(\mathbf{2 5 - 3 2} \cdot \mathbf{Z} \mathbf{n}_{2}\right.$, Figure 8$)$ and their anion binding abilities evaluated using colorimetric indicator displacement assays with three different indicators: pyrocatechol violet, bromopyrogallol red and pyrogallol red.[18] The new complexes had alanine non-binding sidechains, and shortened binding sidechains (with respect to the ornithine residues used before). For comparison, the non-macrocyclic receptor $\mathbf{3 3} \cdot \mathbf{Z n}$, was included in the study.

Chemosensing ensembles comprising the cyclic pseudopeptidic receptors $\mathbf{2 5}-\mathbf{3 2} \cdot \mathbf{Z n}_{2}$ and pyrocatechol violet show enhanced discrimination between PPi and ATP/ADP in comparison to those containing the simple bis(Zn(II)-DPA) complex $\mathbf{3 3} \cdot \mathbf{Z n}_{2}$. The higher selectivity can be due to steric blocking of the larger anions by the non-binding side chains on the cyclic peptide scaffold. The best discrimination between anions was observed for receptors $\mathbf{2 9} \cdot \mathbf{Z n}_{2}$ and $\mathbf{3 1} \cdot \mathbf{Z n}_{2}$ in which the $\mathrm{Zn}$ (II)-DPA sites are appended to a tetraoxazole scaffold, with spacers of two methylene units. These structures provide both the flexibility required for induced-fit binding of PPi and the steric blocking of other larger anions. The selectivity of the chemosensing ensembles was also affected by the indicator used, with pyrogallol red and bromopyrogallol red both providing enhanced discrimination between polyphosphate ions with respect to pyrocatechol violet. Ensembles of all three indicators with the cyclic peptides $\mathbf{2 5}-\mathbf{3 2} \cdot \mathbf{Z n}_{\mathbf{2}}$ provide significant color changes visible to the naked eye and are effective in Krebs saline solution, enabling the ratiometric detection of PPi in the presence of a large excess of ATP.
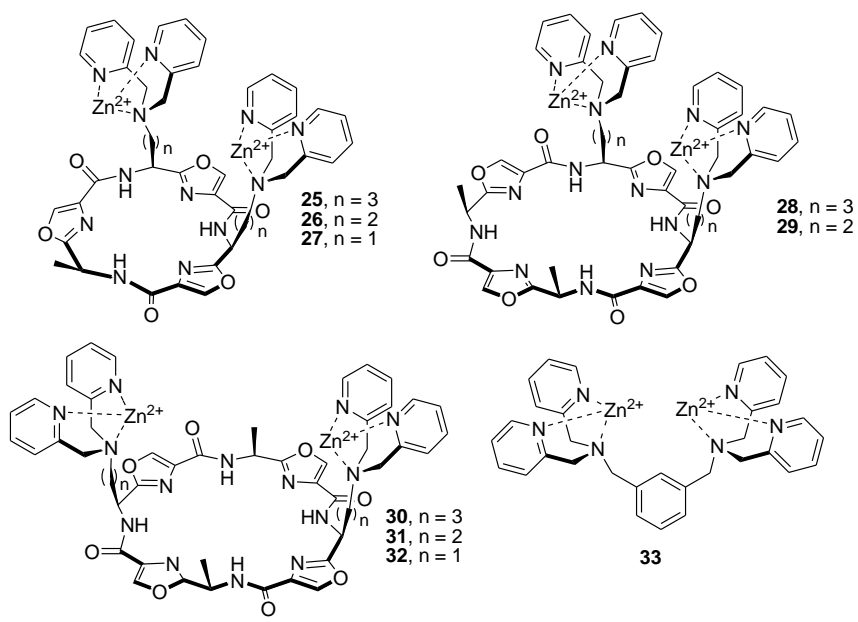

Figure 8. Structures of sensors 25-33.

Later, the same group reported on another family of oxazole-based pseudopeptides with Zn(II)-DPA sites (34$\mathbf{3 6} \cdot \mathbf{Z n}$, Figure 9), covalently functionalized with a coumarin unit, so that they can act as intramolecular fluorescent 
indicator displacement assays. The complexes $\mathbf{3 4 - 3 6} \cdot \mathbf{Z n} 2$ show the same overall behavior: a large fluorescent enhancement in the presence of PPi and minimal changes in emission upon the addition of either ADP or ATP.

The ability of these molecules to selectively bind to pyrophosphate was compared with that of the analogous receptors in intermolecular IDAs with a similar coumarin indicator.[19] For example, $\mathbf{3 4} \cdot \mathbf{Z} \mathbf{n}_{2}$ shows significantly higher selectivity for PPi compared to the analogous $\mathbf{2 8} \cdot \mathbf{Z n}_{2}$, although with a lower affinity.

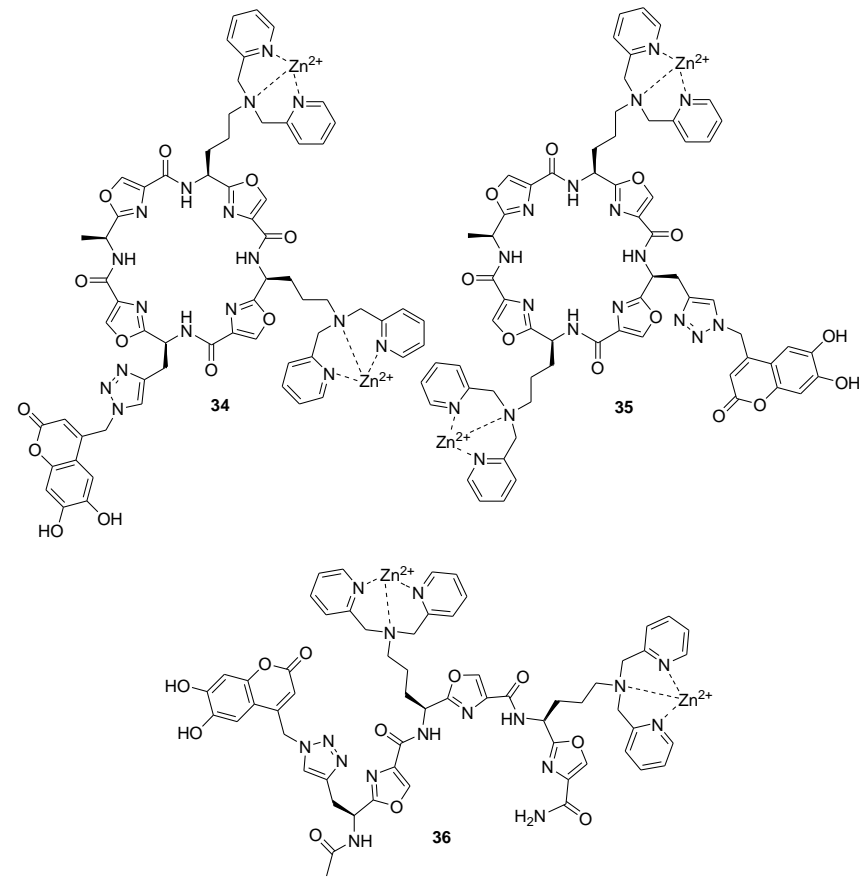

Figure 9. Chemical structure of the sensors 34-36.

On the other hand, $\mathbf{3 5} \cdot \mathbf{Z n}_{2}$ does not display any improvement in either affinity or selectivity over the analogous indicator displacement approach with $\mathbf{3 0} \cdot \mathbf{Z} \mathbf{n}_{2}$, pointing out that the position of the indicator on the scaffold is a key parameter. The two $\mathrm{Zn}$ (II)-DPA binding sites have to be adjacent to each other on the pseudopeptide scaffold, as also supported by the high selectivity observed for the open receptor $\mathbf{3 6} \cdot \mathbf{Z n}_{2}$. The sensitivity of these intramolecular IDAs is lower than that of the intermolecular counterparts: both $\mathbf{3 4} \cdot \mathbf{Z n}_{2}$ and $\mathbf{3 6} \cdot \mathbf{Z n}_{2}$ can detect PPi anions at low micromolar levels, while $\mathbf{3 0} \cdot \mathbf{Z} \mathbf{n}_{2}$ is able to detect nanomolar concentrations of the same anion.

As seen before, one potential application of fluorescent PPi sensors is to monitor enzymatic processes in real time. A fluorescence assay was used to monitor the activity of pyrophosphatase, an enzyme which catalyzes the hydrolysis of PPi to two phosphate ions in the presence of magnesium. Pyrophosphatase was added to a solution containing either $\mathbf{3 3} \cdot \mathbf{Z n}_{2}$ or $35 \cdot \mathbf{Z n}_{2}$ and excess PPi in Tris buffer and the fluorescence response was then measured over time. A decrease in fluorescence intensity was observed, indicating a reduction in PPi concentration, a result of the enzyme activity. These results suggest the general applicability of pseudopeptidic PPi sensors for monitoring the enzymatic activity of inorganic pyrophosphatase.

\subsection{Molecular beacons as biosensors}

The sensing of nucleic acids is of great interest for biomedical research. Molecular beacons (MBs), in which a synthetic oligonucleotide is functionalized with two chromophores, are often used in this field. Hybridization with a complementary DNA strand provokes a conformational change of the sensor, which modifies the interaction between the chromophores, and produces a specific spectroscopic signal that is used for detection.

Peptide beacons (PBs) are MBs derived from oligopeptides; they are less used, because small oligopeptides rarely form stable folded structures, and they can then undergo a spectroscopically detectable conformational change upon binding to an analyte.

The research group led by Plaxco reported two pyrenebased peptide beacons to monitor polypeptide-protein and polypeptide-oligonucleotide interactions (Figure 10).[20] The first probe, 37, is an excimer-based PB designed for an antibody diagnostic of HIV infection. The human immunodeficiency virus type 1 (HIV-1) matrix protein $\mathrm{p} 17$ is highly antigenic; a six-residue epitope present in it is used as the basis of the PB. In the absence of its target, the PB displays a large excimer peak centered at $475 \mathrm{~nm}$. Upon titration with human anti-p17 antibody, the excimer emission decreases until almost disappearing for $1: 1$ molar ratio. The specificity of $\mathbf{3 7}$ was assessed by titration against a mixture of human IgG: a much smaller reduction in signal was observed.
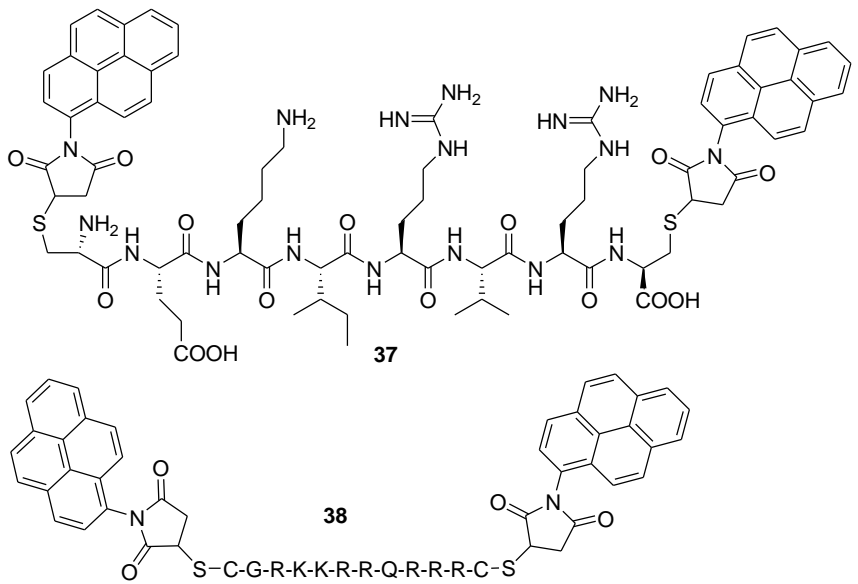

Figure 10. Structure of the molecular beacons $\mathbf{3 7}$ and $\mathbf{3 8}$.

The second probe, $\mathbf{3 8}$, is an excimer-based PB designed for an oligonucleotide target: the TAR RNA hairpin of HIV-1. The interaction targeted in this application is challenging: when bound to the major groove of a U-rich stem-loop target RNA, the peptide adopts a $\beta$-hairpin structure with close ends, and thus terminally conjugated dyes will not experience significant spatial segregation upon complex formation. In spite of that, a 50\% reduction in excimer emission upon target binding was observed, probably because of the strong geometry-dependence of excimer formation. This pioneering 
system proved the potential efficacy of peptide beacons as sensors for biomolecules, while the low ratio between the intensities of the bound/unbound states represent their major pitfall.[20]

Schmuck et al. reported on a pyrene-based PB, 39, containing two Trp-Thr-Lys tripeptide units, each attached via its $\mathrm{C}$-terminus to a central lysine spacer. At its $\mathrm{N}$-terminus, each peptide arm is functionalized with a pyrene moiety (Figure 11).[21] Compound 39 efficiently interacts with double-stranded DNA (ds-DNA), as demonstrated by spectroscopic studies. The fluorescence emission spectrum of 39 displays a strong band at $\lambda=490 \mathrm{~nm}$ (pyrene excimer) and a significantly weaker one at $406 \mathrm{~nm}$ (pyrene monomer), indicating that the two pyrene units in $\mathbf{3 9}$ are mostly $\pi$-stacked in free solution. Therefore, 39 adopts an intramolecularly folded structure, as required for an MB. Upon binding to dsDNA, this excimer emission decreases and finally disappears, and the monomer emission increases accordingly, revealing that 39 binds to the polynucleotide, causing the unfolding of the molecule. The spectroscopic changes depend on the type of polynucleotide and are stronger for $\mathrm{p}(\mathrm{dA} \cdot \mathrm{dT})_{2}$ and weaker for $\mathrm{p}(\mathrm{dG} \cdot \mathrm{dC})_{2}$ and calf-thymus DNA (ctDNA) having $\mathrm{ca} .60 \%$ AT and $40 \%$ GC. Fluorimetric titration data showed that the affinity of $\mathbf{3 9}$ for the nucleic acids was in the micromolar range, with a selectivity for $\mathrm{p}(\mathrm{dA} \cdot \mathrm{dT})_{2}(K \mathrm{~s}=20 \mu \mathrm{M})$ over $\mathrm{p}(\mathrm{dG} \cdot \mathrm{dC})_{2} \quad(K s=300 \mu \mathrm{M})$. Confocal laser scanning microscopy (CLSM) was used for DNA imaging in live Hela cells. This technique showed that $\mathbf{3 9}$ is capable of entering the cell, reaching the nucleus, and binding to the nucleic acids, giving rise to a strong fluorescence signal coming from the nucleus, with a very high signal-to-background ratio (>1000) between the nucleus and the cytoplasm. Lacking any general cytotoxicity, 39 might be of interest for applications in diagnostics.

However, pyrene is not an ideal fluorophore, due to its low quantum yield and emission in the blue region, which is unfavorable for potential applications in biological systems. Therefore, the same group developed a new peptide beacon with higher sensitivity and a significant red shift upon DNA binding (Figure 11). Probe 40 contains two Gly-Ser-Lys tripeptide arms attached via their C-terminus to a central lysine spacer. The N-termini of the peptide arms were functionalized with a FRET pair, a naphthalene donor and a dansyl acceptor to achieve a ratiometric response.[22] The emission spectrum of free $\mathbf{4 0}$ contains a strong band at 383 $\mathrm{nm}$, due the naphthalene moiety, and a much weaker band at $535 \mathrm{~nm}$, due to the dansyl moiety.

This indicates that $\mathbf{4 0}$ adopts an unfolded structure in free solution that prevent the energy transfer between the chromophores. Upon addition of $\mathrm{p}(\mathrm{dA} \cdot \mathrm{dT})_{2}$, the emission at $383 \mathrm{~nm}$ decreases, while the emission at $535 \mathrm{~nm}$ increases accordingly. This is the result of the folding of $\mathbf{4 0}$, provoked by $\mathrm{p}(\mathrm{dA} \cdot \mathrm{dT})_{2}$ binding. The large red shift $(c a .160 \mathrm{~nm})$ produced in the emission band is a highly desirable feature for a ratiometric fluorescence probe, because it helps to increase the detection accuracy. $\mathbf{4 0}$ can be also used for the ratiometric detection of different types of polynucleotides, as it exhibits a larger fluorescence response for AT-rich polynucleotides than GC-rich ones.

An imaging experiment with $\mathbf{4 0}$ and A549 cells using confocal laser scanning microscopy (CLSM) showed bright green fluorescence from individual fixed cells treated with $\mathbf{4 0}$, showing that $\mathbf{4 0}$ has entered the cell and reached the nucleus. This was further confirmed by co-localization studies with DAPI, a well-established dye for DNA staining in the nucleus.

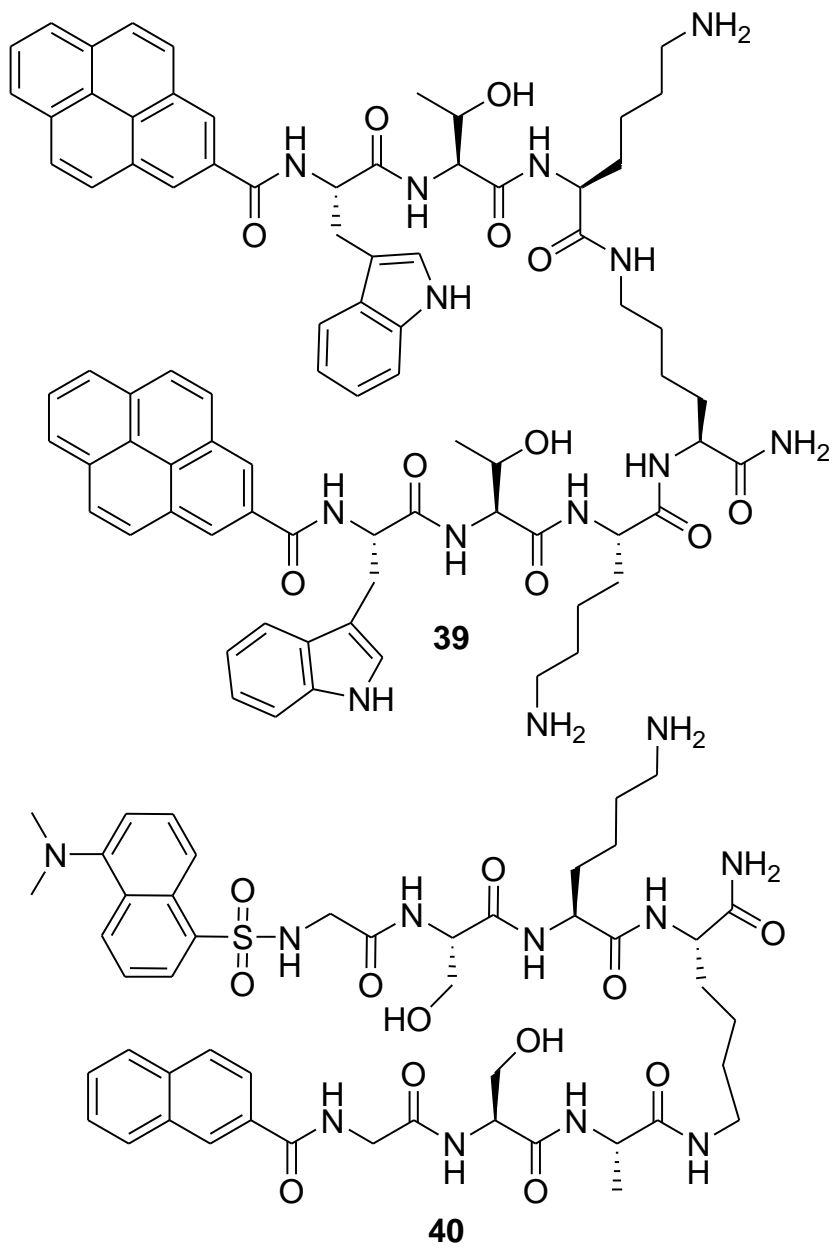

Figure 11. Structure of the molecular beacons for DNA, 39 and 40.

The same group exploited the principle of folded-unfolded molecular beacons to develop the fluorophore functionalized cationic oligopeptides $\mathbf{4 1}$ and $\mathbf{4 2}$ to ratiometrically monitor heparin in aqueous media (Figure 12).[23] Heparin is a highly sulfated glycosaminoglycan with high negative-charge density. It is used as an anticoagulant to prevent thrombosis during surgery and to treat thrombosis, but its overdose can cause negative effects. The peptide beacons contain two LysLys-Ser-Gly arms attached through their C-terminus to a central lysine. The N-terminus of each peptide arm was functionalized with a fluorophore. 41 was labelled with pyrene units to form a monomer-excimer switching probe, while $\mathbf{4 2}$ was equipped with a fluorescence resonance energy transfer (FRET) pair: naphthalene (donor) and dansyl (acceptor), to achieve a ratiometric response. The design of the two probes was inspired by the naturally occurring highly 
cationic peptide protamine sulfate, an antidote for heparin overdose, and the amino acids used were chosen to render the overall probe sufficiently polar for applications in water.

The residues of the four Lys carry positive charges at physiological $\mathrm{pH}$, driving the binding of $\mathbf{4 1}$ and $\mathbf{4 2}$ to the negatively charged heparin. This binding is accompanied by a change in the conformation of the peptide beacons, which is reflected in changes of pyrene monomer - excimer emission in $\mathbf{4 1}$ as well as changes in the efficiency of the FRET process between two fluorophores in $\mathbf{4 2}$.

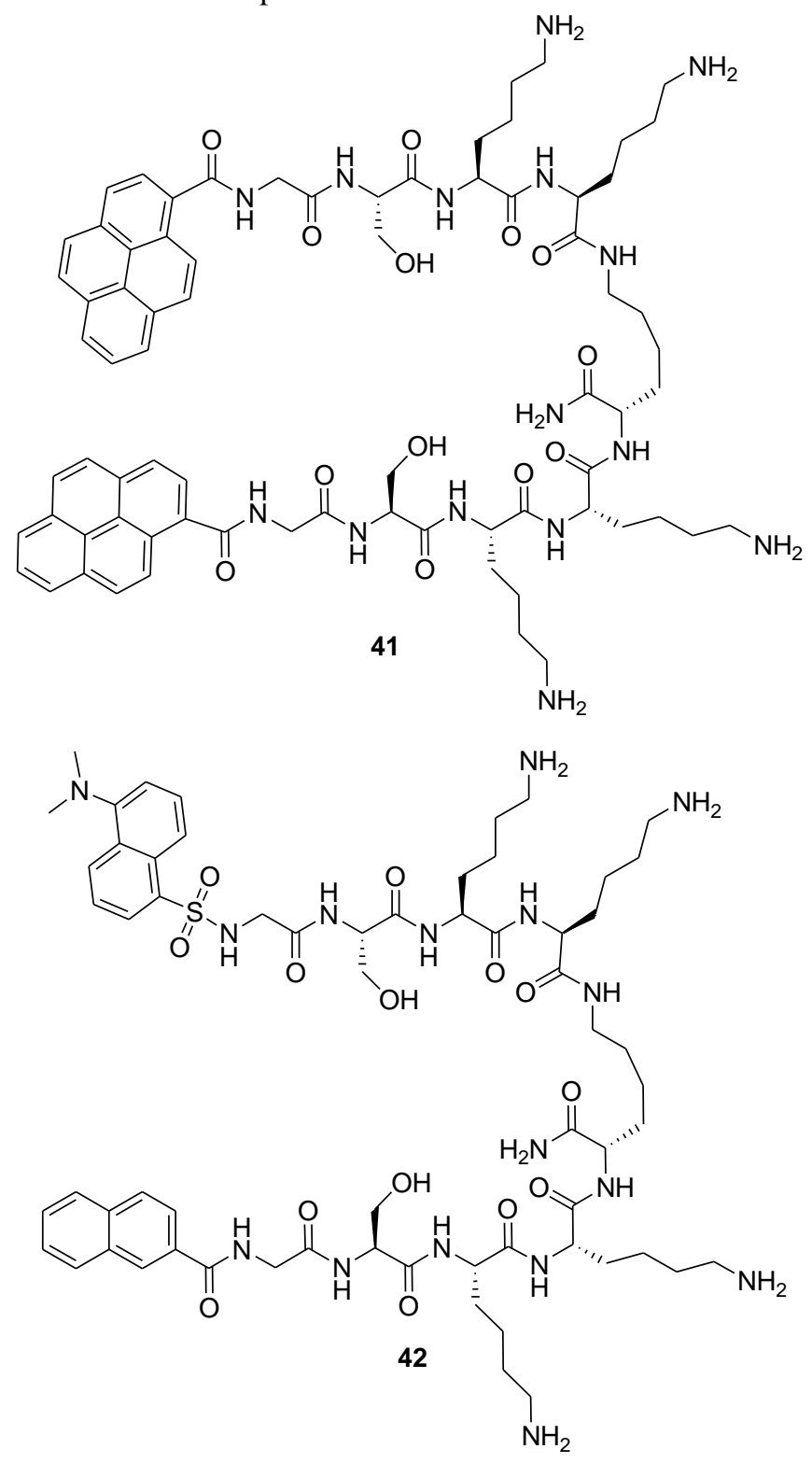

Figure 12. Molecular beacons for heparin: $\mathbf{4 1}$ and $\mathbf{4 2 .}$

The emission spectrum of free $\mathbf{4 1}$ features a strong band at $406 \mathrm{~nm}$ (pyrene monomer) and a significantly weaker one at $499 \mathrm{~nm}$ (pyrene excimer), indicating an unfolded structure. Upon binding to heparin, the monomer emission decreases while the excimer emission increases, suggesting the stacking of the pyrene units.

Similarly, compound 42 emits around $380 \mathrm{~nm}$, a value typical for naphthalene chromophore. After heparin addition, the naphthalene emission decreases while a new strong band appears around $525 \mathrm{~nm}$, which corresponds to the dansyl chromophore. This change highlights the triggering of the FRET mechanism. These fluorescence titrations provided the binding constants of $\mathbf{4 1}$ and $\mathbf{4 2}$ with heparin: $1.3 \cdot 10^{6} \mathrm{M}^{-1}$ and $2.9 \cdot 10^{6} \mathrm{M}^{-1}$, respectively. Concentration of heparin repeating unit as low as $30 \mathrm{nM}$ can be detected using $1.0 \mu \mathrm{M}$ solution of $\mathbf{4 1}$ or $\mathbf{4 2}$, a fact that could allow the use of $\mathbf{4 1}$ and $\mathbf{4 2}$ for practical monitoring applications, being the therapeutic dosing level of heparin is the $0.08-3.2 \mu \mathrm{M}$ range.

The selectivity of probes $\mathbf{4 1}$ and $\mathbf{4 2}$ towards heparin was confirmed by the fact that biologically relevant species such as adenosine, adenosine monophosphate (AMP), adenosine triphosphates (ATP), phosphate (Pi), pyrophosphate (PPi), ctDNA, glucose, bovine serum albumin (BSA), hyaluronic acid (HA), chondroitin sulfate (Chs), glutamic acid and aspartic acid did not cause significant changes in their fluorescence intensity ratios. The ability of sensing heparin was also confirmed in diluted fetal bovine serum (FBS), without major changes with respect to aqueous solution. In conclusion, the strong fluorescence and large Stokes shift of $\mathbf{4 1}$ and $\mathbf{4 2}$ could be useful for heparin quantification without interferences from other biomolecules. The only drawback of these systems could arise from the need to excite in the UV range (340 nm for $\mathbf{4 1}$ and $270 \mathrm{~nm}$ for $\mathbf{4 2}$, respectively).

Schmuck et al. reported on the fluorescent probe 43,[24] with two symmetric peptidic arms that are equipped with a guanidiniocarbonyl pyrrole moiety (a good anion-binding site, Figure 13). Each arm contains one lysine for chargecharge interactions and one tryptophan for $\pi-\pi$ interaction with nucleobases. The central spacer is functionalized with a green emitting aminonaphthalimide fluorophore as reporter unit. The structure of the pseudopeptidic probe $\mathbf{4 3}$ is very flexible and designed to bind nucleotides like a pincer. Probe 43 showed only a weak fluorescence emission at $540 \mathrm{~nm}$ in neutral aqueous conditions. The fluorescence intensity increased by more than 4-fold upon addition of ATP, with a calculated binding constant of $2.2 \cdot 10^{5} \mathrm{M}^{-1}$, and allowing the sensing of submicromolar concentrations of ATP. Probe $\mathbf{4 3}$ showed strong binding affinity (in the order of $10^{5} \mathrm{M}^{-1}$ ) towards all nucleoside triphosphates (GTP, CTP, TTP and UTP) and also pyrophosphates, while nucleoside diphosphates (ADP, UDP) showed lower binding affinities. The fluorescence enhancement by these polyphosphates was found to be in the order ATP > GTP > UTP > CTP > TTP > $\mathrm{PPi}>>\mathrm{ADP}>\mathrm{UDP}$. In contrast, the fluorescence change was not induced by monophosphorylated species or by other anions $\left(\mathrm{SO}_{4}^{2-}, \mathrm{NO}_{3}^{-}, \mathrm{HCO}_{3}^{-}, \mathrm{CH}_{3} \mathrm{COO}^{-}\right)$. These results suggest that $\mathbf{4 3}$ is a useful probe for the overall detection of nucleoside triphosphates and pyrophosphate, lacking selectivity within this group of analytes. Molecular modelling for the complex between a simplified version of probe $\mathbf{4 3}$ and pyrophosphate (PPi) showed that the pseudopeptide binds tightly to the negatively charged oxygen atoms of the PPi by ion pair interactions with both guanidiniocarbonyl pyrrole moieties and with ammonium groups of lysine. Several hydrogen bonds are additionally formed. The observed larger fluorescence of triphosphates over di- or monophosphates 
may be ascribed to the difference in electrostatic interaction with GCP and lysine. The different fluorescence response among nucleoside triphosphates is probably due to distinct interactions of the nucleobases with the tryptophan residues and the naphthalimide fluorophore.

Probe $\mathbf{4 3}$ was also studied by fluorescence microscopy in cultured HeLa cells. Cellular ATP concentration is normally in the millimolar range. Oligomycin inhibits ATP synthesis and decreases cellular ATP levels. One set of HeLa cells was treated with $10 \mathrm{mM}$ oligomycin for $30 \mathrm{~min}$ and the other set was not. The cells were then treated with probe $\mathbf{4 3}$ and washed. Probe $\mathbf{4 3}$ displayed green fluorescence in the normal HeLa cells, whereas only a very weak fluorescence was observed in the cells treated with oligomycin. These results indicate that probe $\mathbf{4 3}$ can cross the cell membrane and detect intracellular ATP, while its cytotoxicity was found to be low.

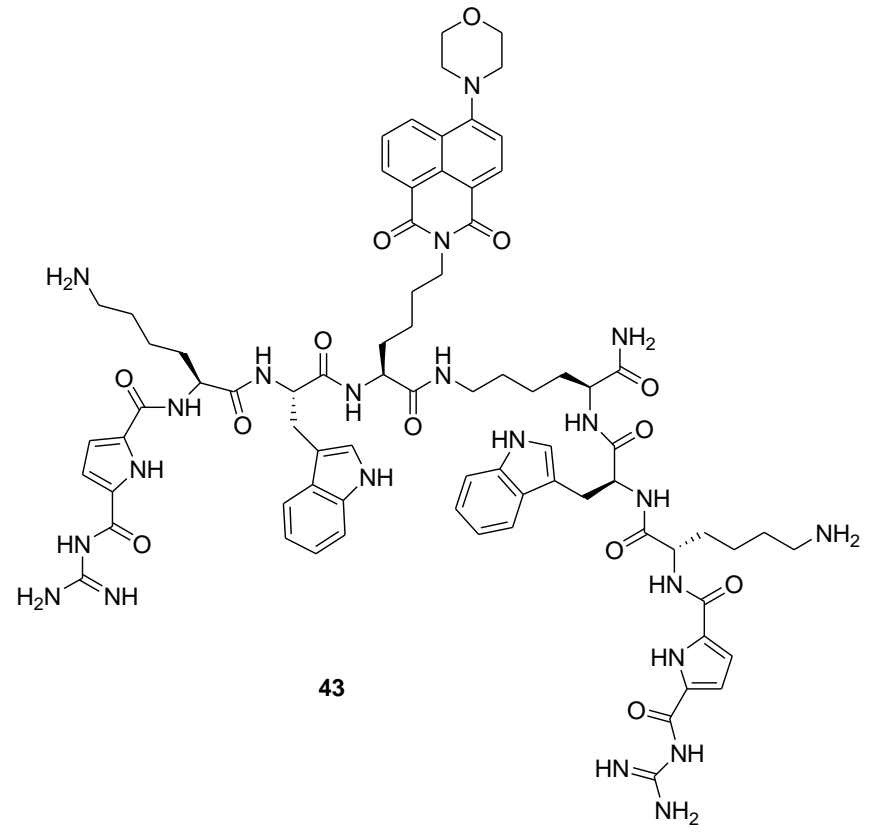

Figure 13. Molecular beacon for ATP, 43.

\section{PSEUDOPEPTIDES AS TRANSPORTERS}

Some pseudopeptidic molecules have been also used as molecular systems to transport ions though cell membrane, as a way to control ion permeability. As a consequence, pseudopeptidic ion transporters (or ionophores) are becoming valuable tools offering excellent opportunities as therapeutic drugs or for diagnosis.[25] The manipulation of the cell membrane ion permeability by modulation of the ion balance can be used as a mechanism for cell death induction in abnormally growing cells, like cancer cells, or to kill harmful microorganisms. It is important to highlight that ionophores do not rely on active metabolism to exert their biological activity.[26] Thus, they can be especially useful in the treatment of persistent infections. The deficient function of normal transport mechanisms lead to the inefficient regulation of ion concentration levels, producing diseases known as channelopathies.[27] Artificial ionophores could be used in channel replacement therapies for the treatment of these diseases, and pseudopeptidic molecules are privileged structures in this field. For instance, a special family of ionophores is the one formed by macrocyclic peptides[28] and depsipeptides.[29] The well-known and prototypical example is Valinomycin,[30, 31] which shows the largest reported $\mathrm{K}^{+} / \mathrm{Na}^{+}$selectivity.[32] Most of these compounds are characterized by an inner polar binding site for the cation, surrounded by an outer hydrophobic shell to insert and diffuse in the membrane. One seminal example corresponds to the work from Ghadiri's group, based on cyclic peptides.[33] They designed a series of macrocyclic peptides with an even number of alternating D/L-amino acids, which adopt a flat ring-shaped conformation, with the side chains pointing out of the macrocyclic cavity and, accordingly, setting the peptide bond perpendicular to the ring (Figure 14).
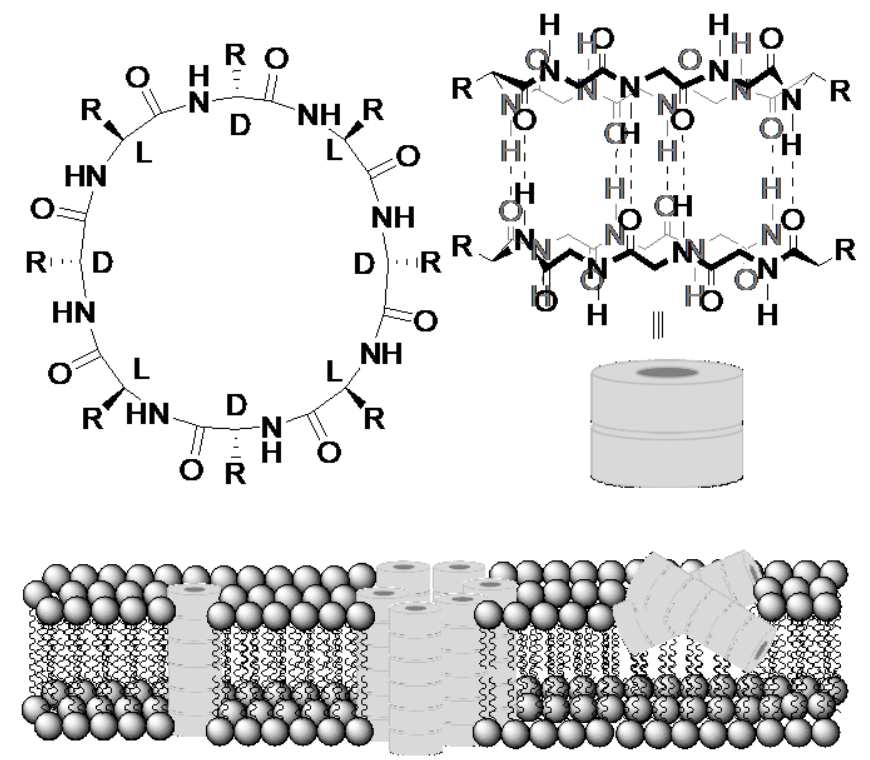

Figure 14. Self-assembling of macrocyclic peptides into nanotubes able to disropt the cell-membrane integrity.

This geometry generates the stacking of the macrocycles in a $\beta$-sheet fashion through $\mathrm{H}$-bonding interactions, finally selfassembling into a nanotube.[34] The tubes thus constructed contain an inner channel, for which the size can be easily modulated by the size of the macrocycle. These nanotubes are able to stack within the cell membrane,[35] rendering the formation of channels and pores that permit ion trafficking that produces the cell death. Thus, these cyclic peptides kill bacteria very efficiently when the right combination of the amino acids was optimized.[36] The authors concluded that the most efficient and selective drugs correspond to those peptides displaying a specific balance of hydrophobic and hydrophilic cationic side chains. This allows the localization in the lipid bilayer and the establishment of attractive interactions with the negatively charged bacterial exterior. Despite the detailed mechanism for the depolarization of the membrane is not fully understood, the data shows that the cavity size of the nanotube has little effect on the activity, and points to the efflux of protons (or hydronium cations) as the main factor. Interestingly, the mammalian cell toxicity of these cyclic peptides can be drastically reduced by glycosylation, maintaining their activities against multidrug- 
resistant Gram-positive species.[37] Based on these peptidic macrocycles, Jolliffe and co-workers have decorated the nanotubes with polymeric coronas leading to self-assembled nanomaterials in model lipid bilayers,[38] which are responsive to thermal stimuli.[39]

Also Ghadiri's group prepared cyclic tetrapeptides from hydrophobic $\beta$-amino acids and they found that the cyclic structure made of homotryptophane (HTrp) displayed transport properties similar to the original nanotubes from alternating D/L-cyclic peptides (Figure 15, 44).[40] Related to this field, Granja and co-workers have used alternative designs to construct similar peptide-like macrocycles that are able to form nanotubes in lipid bilayers.[41-43] Thus, they prepared cyclic peptides made of $\alpha$-amino acids and 3aminocycloalkanecarboxylic acids ( $\gamma$-Aca) leading to $\alpha, \gamma-$ cyclic peptides (Figure 15, 45-46). Tryptophan residues were included for membrane insertion and the glutamine side chain was used to assist in their preparation by solid-phase peptide synthesis.[44]

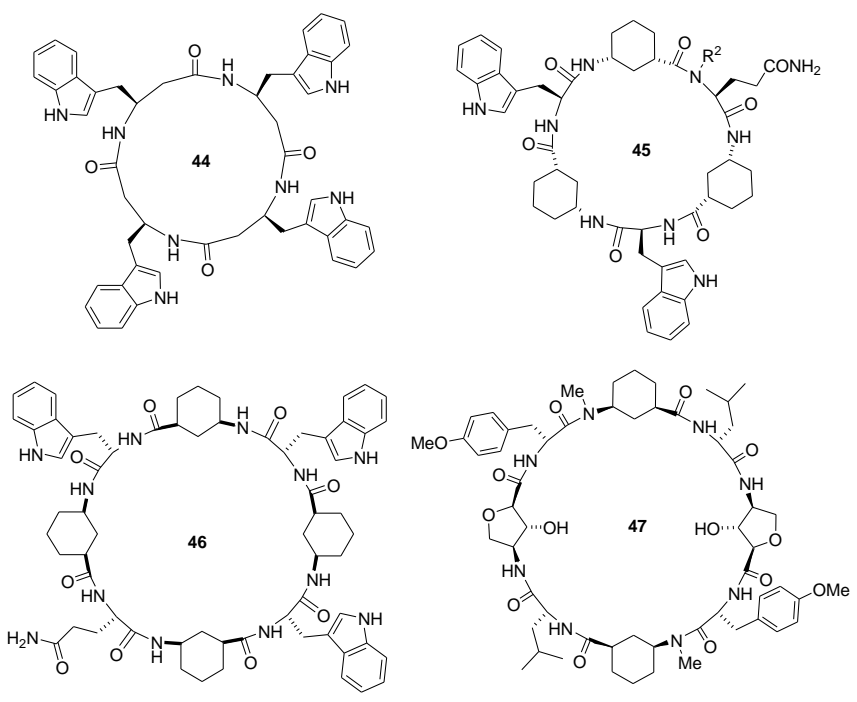

Figure 15. Macrocyclic peptide-like molecules able to transport ions through lipid bilayers as models of cell membranes.

Specifically, the hexameric macrocycle $\mathbf{4 5}$ was able to transport protons (or hydronium ions) through a lipid bilayer, but its cavity size proved to be too small for transporting metal ions. However, the octameric macrocycle 46 was able to transport sodium, potassium and cesium ions with selectivity rates following the lyotropic series. Intriguingly, the rate for the transport of $\mathrm{Na}^{+}$was ca. $25 \%$ faster than the expected for its free mobility in bulk aqueous solution. A thorough analysis including molecular dynamic simulations suggested that the inner hydrophobic lumen of the tubes produced by the methylenes at $\mathrm{C} 2$ of $\gamma$-Aca, and the hydration sphere of the cation payed the major role in the transport efficiency. Considering these results, the same group has made important efforts in the functionalization of the inner cavity of the macrocycles in order to increase the transport selectivity.[45] This comprised the inclusion of $\mathrm{Ag}^{+}$cation or oxalic acid,[46] as well as the anti-cancer drug cis-platinum.[47] This last example is especially interesting since the platinum-inclusion complex within the cyclic peptide showed cytotoxic activity against A2780 ovarian cancer cell lines independent of acquired platinum resistance. In an additional attempt to make the interior of the tube more hydrophilic the cyclopeptide $\mathbf{4 7}$ was prepared, projecting two hydroxyl groups to the inner cavity of the macrocycle (Figure 15). Unexpectedly, this compound did not self-assemble in a flat stacked conformation, but a V-shaped folding was obtained both in solution and in solid state. Interestingly, this folded conformer formed spherical hexameric aggregates with both carbonate and chloride anions, making $\mathbf{4 7}$ an efficient chloride transporter in model membranes.[48] Overall, the results obtained with this family of cyclic non-natural peptide-like molecules underscore the versatility of the systems for transport and delivery applications with potential biomedical impact.

The peptidic architectures have been also combined with classical crown ethers in order to exploit the characteristics of these macrocyclic synthetic ethers. As a representative example, a 4-aminobenzo-15-crown was connected to monensin A, leading to a sodium ionophore with potent antiGram-positive bacteria activity.[49] Related to those, Voyer designed a family of ion channels,[50] preparing oligopeptides with hydrophobic side chains and non-natural amino acids bearing crown ethers, specifically located in the peptidic sequence (48a-c, Figure 16).<smiles>[R]C[C@H](NC(=O)[C@H](CC(=O)[C@H](CC(C)C)NC(=O)[C@H](CC(C)C)NC(=O)[C@H](C[R])NC(=O)[C@H]([X])CC(C)C)CC(C)C)C(=O)N[C@@H](CC(C)C)C([Y])=O</smiles>

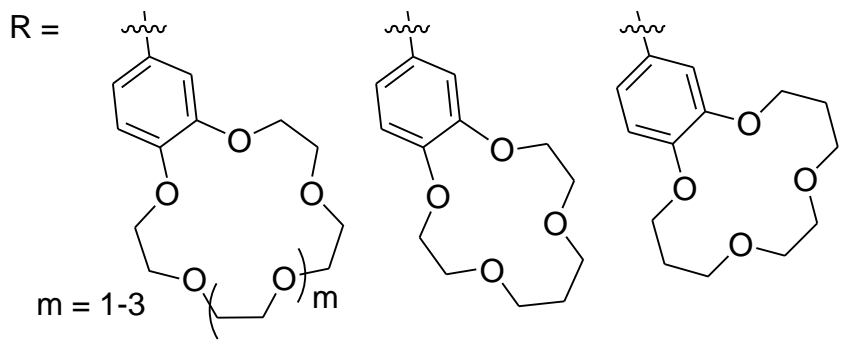

Figure 16. Nanochannels 48a-c made of peptide-crown ether conjugates.

The peptidic backbone folds into an $\alpha$-helix when located in the membrane, which aligns the crown ether rings into a polar pore for the cations to traffic.[51] Thus, the size of the crown ether defines the space of the pore, while the pore length is delimited by the length of the peptide, allowing the conjugates to promote the transport of cations through the membranes. Despite the nanostructures did not display antimicrobial activity, they displayed promising cytotoxicity against different cancer cell lines.[52] The peptides have to be $3-4 \mathrm{~nm}$ long ( $\mathrm{n}=2$ in a 14-mer peptide) to cross the cell membrane for showing activity.[53] More recently, a strategy to improve the selectivity against cancer cells of these systems 
was proposed.[54] Decorating the conjugates with negatively charged dipeptides linked through their $\mathrm{N}$ - or C-termini resulted in a loss of activity (Figure 16, $\mathrm{n}=\mathrm{m}=2, \mathrm{X}=\gamma$-Glu$\gamma$-Glu-, $\mathrm{Y}=\mathrm{OH})$. This dipeptide chain is specifically cleaved by a membrane protein (PSMA), which is over-expressed in certain prostate cancer cell line. This resulted in the release of the active drug on the tumor cells, thus increasing the selectivity of the drug.

Inspired by the natural peptide gramicidine $\mathrm{A}, \mathrm{Li}$ and $\mathrm{Hou}$ and co-workers designed a family of pseudopeptidic channels (49a-c) formed by a central foldamer core and pending trisPhe peptidic arms (Figure 17).[55] The foldamer core is built by H-bonded aromatic hydrazides that are known to show a helical conformation.[56] Oligomers with different lengths were prepared and studied as ion transporters by patch clamp experiments. These molecules displayed a selectivity for ammonium cation that is comparable to the one exerted by the natural peptide gramicidin A. Additional experiments suggested that the transport efficiency could be improved by adding polar groups in the structure for a more efficient dehydration of the cation upon sliding along the lumen of the channel.<smiles>[R]CCC(=O)N[C@@H](Cc1ccccc1)C(=O)N[C@@H](Cc1ccccc1)C(=O)N[C@@H](Cc1ccccc1)C(=O)O[Na]</smiles>

Figure 17. Transmembrane channels based on an artificial foldamer core decorated with tri-Phe anchors.

The group of Hou has also recently developed a family of tubular molecules that are able to insert in lipid bilayers defining transmembrane channels. [57] These pseudopeptidic structures bear a common central pillar[n]arene $(n=5,6)$ moiety to which peptidic strands are attached through their Nterminus using glycolic acid connectors (50-52, Figure 18). The D/L-alternating configuration of the amino acids in the peptidic arms set the side chains toward the outer face of the tube, thus being in contact with the lipidic phase when the channel is inserted in the membrane. Moreover, this disposition favors the establishment of intramolecular $\mathrm{H}-$ bonding between contiguous peptidic strands, further stabilizing the tubular shape. The size of the cavity in the central core and the nature of the peptidic arms modulate the properties of the molecules thus prepared. For instance, tubular pseudopeptides of different sizes $(\mathrm{n}=5,6)$ and bearing alternating D/L-Phe tripeptides $(\mathbf{5 0 a}, \mathbf{b})$ have shown to transport amino acids through lipid bilayers, showing a high stereoselectivity for L-phenylalanine.[58] The tubular molecules based on pillar[5]arene and bearing Arg residues at different positions of the peptidic arms (51a-c) showed to be voltage-gated channels, thanks to the ability of the systems to respond to electric fields.[59] The charged residues make the systems more soluble in aqueous medium and the channels can be pushed into the lipid bilayer or extracted to the aqueous environment upon applying an external voltage. When embedded within the bilayer, the systems are able to transport potassium ions, and thus, the voltage trigger can turn on/off the transport of this cation.

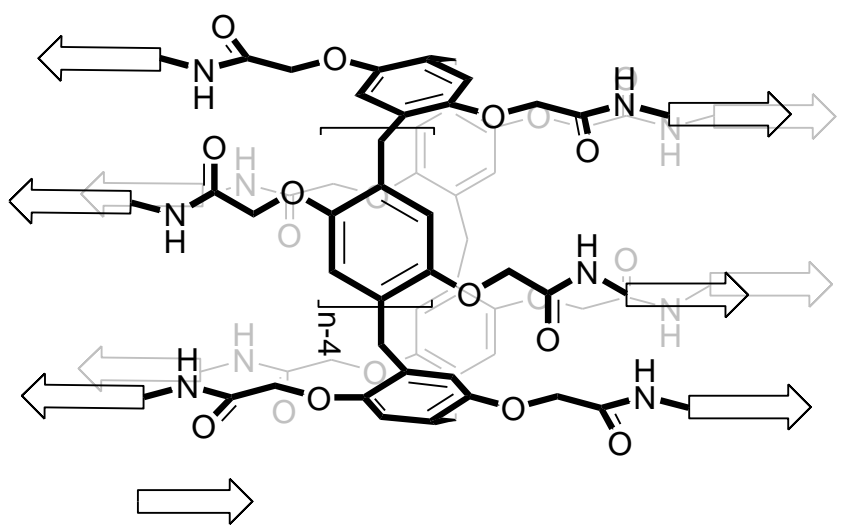

$\mathrm{n}=5,6$ D-Phe-L-Phe-D-Phe-OH (amino acid channel)

$50 \mathrm{a}, \mathrm{b}$

$\mathrm{n}=5 \quad$ L-Phe-D-Phe-L-Arg-OEt (voltage-gated channel)

51a-c L-Phe-D-Arg-L-Phe-OEt (voltage-gated channel)

51a-c L-Arg-D-Phe-L-Phe-OEt (voltage-gated channel)

$\mathrm{n}=5 \quad \mathrm{~L}-\mathrm{Trp}-\mathrm{OH}$ (antibacterial channel)

52a-d D-Leu-L-Trp-OH (cytotoxic channel)

L-Leu-D-Leu-L-Trp-OH (cytotoxic channel)

D-Leu-L-Leu-D-Leu-L-Trp-OH (cytotoxic channel)

Figure 18. Artificial ion channels based on pillar[n]arene decorated with peptide strands.

All these systems serve as models of natural membrane proteins and peptides that transport ions through it. This fact has a tremendous biomedical potential, as the same research group has recently demonstrated. They prepared several tubular pseudopeptides from the pillar[5]arene and bearing peptides of different lengths, always containing hydrophobic residues (52a-d, Figure 18).

The presence of a Trp at the $\mathrm{C}$ termini of the strands is necessary to maximize the ability of the systems to interact with the membranes. Different experiments showed that the molecules efficiently inserted in the lipid bilayers, depolarizing the cell membranes and inducing cell toxicity in 
Gram-positive bacteria, with IC50 values in the micromolar range. Very interestingly, although most of the systems also displayed comparable hemolytic activity, the shortest tube showed a very low toxicity in erythrocytes, meaning that this molecule could be an excellent candidate for the further development of potent antibiotics. Actually, since the mechanism of action does not rely on metabolic pathways, the tube proved active and selective for Methicillin-resistant Staphylococcus aureus (MRSA) with very low toxicity for mammalian cells.[60]

Despite anionophores have been less studied than cationophores, the development of small-molecule anion transporters has increased in the last years.[61] Tomich and co-workers focused on the use of short peptides as chloride channels.[62] Inspired by the sequence of several natural chloride channels, these peptides insert into the membrane and form oligomeric bundles.[63] Tomich and colleagues showed that these molecules transport anions across the membranes of liposomes, bilayers and living cells. A representative example is the synthetic PARVGLGITTVLTMTTQSSGSRA peptide, derived from tha glycine-gated chloride channel.[64] The biological activities of these peptides were studied in a series of research papers, $[65,66]$ highlighting the potential of increasing the ion permeability for modulating epithelial barriers and drug delivery.

The group of Gokel studied amphiphilic pseudopeptides as ion channels,[67] formed by a dialkylamine group linked to a peptide sequence by a diglycolic acid connector at the Nterminus, while the $\mathrm{C}$-terminus is capped as an ester (Figure 19). These molecules self-assemble in lipid bilayers forming anion selective functional pores.[68] Using mouse trachea epithelial cells, changes of transepithelial voltages by addition of 53 indicated the repolarization due to chloride transport.[69]

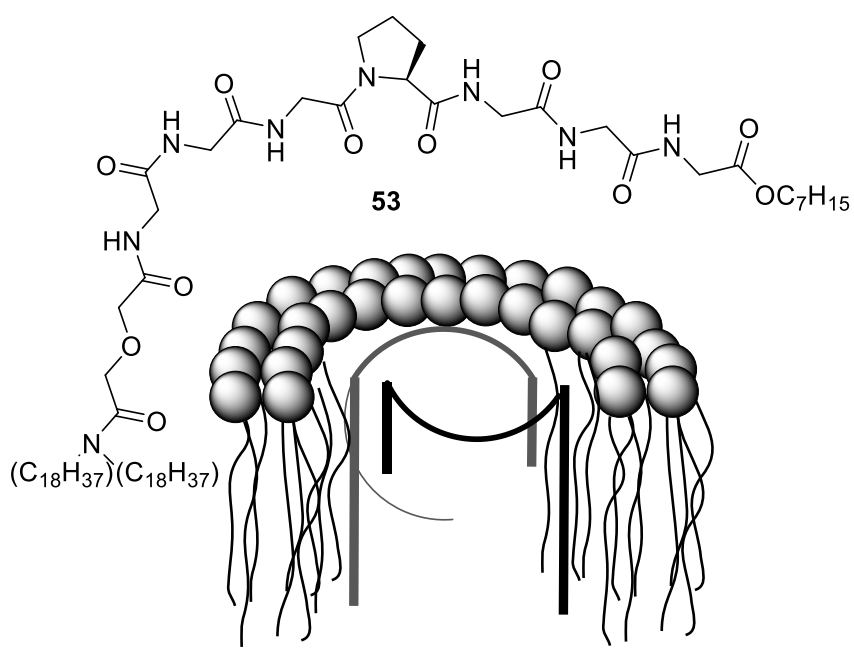

Figure 19. Amphiphilic heptapeptide 53 forming dimers within the lipid bilayer.

Thus, the corresponding whole cell current measurements showed that upon addition of $1 \mu \mathrm{M}$ of $\mathbf{5 4}$, a large increase of the chloride currents was observed. Moreover, compound 54 did not induce immune response in lung tissue in mice, suggesting its potential therapeutic application for the cystic fibrosis treatment.

Yang, Yao and colleagues designed the isophthalamide derivative 54 with two $\alpha$-aminoxyacid arms (Figure 20), which self-assembles into chloride selective channels when located within lipid membranes.[70] These authors showed that 54 can disturb the membrane potential in A7r5 cells.[71] The modulation of the membrane potential affected the voltage gated $\mathrm{Ca}^{2+}$ channel and also the inner $\mathrm{Ca}^{2+}$ concentration. The compound $\mathbf{5 4}$ was tested as vasorelaxant on thoracic aortic rings, leading to the repolarization of membrane potential to deactivate voltage-gated $\mathrm{Ca}^{2+}$ channels in smooth muscle cells. These results showed the potential of 54 to treat hypertension. More recently, the same authors also demonstrated that $\mathbf{5 4}$ increased the chloride permeability of cystic fibrosis human bronquial epithelial cells.[72]<smiles>CC(C)CNC(=O)[C@H](CC(C)C)ONC(=O)c1cccc(C(=O)NO[C@H](CC(C)C)C(=O)NCC(C)C)c1</smiles>

Figure 20. Isophthalamide $\alpha$-aminoxyacid molecule (54) that forms chloride-selective channels.

More recently, the same research group has studied other structurally related pseudopeptidic molecules that elicited chloride-dependent short-circuit current increase in both Calu-3 cell and CFBE41o-cell monolayers.[73]

We have also worked in the field of chloride recognition and transport, by synthesizing small pseudopeptidic tripodal cages (Figure 21) that strongly interact with chloride in aqueous acetonitrile (as demonstrated by ${ }^{1} \mathrm{H}$ NMR titration experiments), in the gas phase (as shown in competition ESIMS assays) and in the solid state (as confirmed by X-ray diffraction studies of single crystals).[74]

The strength of the corresponding chloride complexes depends on the amino acid side chain $\left(R^{1}\right)$ and the substitution at the aromatic 'floor' of the cage $\left(\mathrm{R}^{2}\right)$. Thus, the strength of the interaction from variations in $\mathrm{R}^{2}$ was $\mathrm{Me}>\mathrm{Et}>\mathrm{H}$. This intriguing trend can be explained by the compensation between solvation, preorganization and steric effects, which makes Me the most efficient substitution. The peptidic part of the cages also played a key role in the binding. While the receptors made from aliphatic amino acids show stronger interaction, the cages derived from Phe formed a better defined 1: 1 stoichiometry (by NMR titration) and more efficient inclusion of the chloride anion inside the cage (as confirmed by X-ray diffraction of the corresponding complexes). Very interestingly, the system with $\mathrm{R}^{1}=\mathrm{Bn}$ and $\mathrm{R}^{2}=\mathrm{Me}$ showed a very high selectivity for chloride over 
closely related anions, such as other halides.[75] The crystal structures of the complexes with fluoride, chloride and bromide suggested a reasonable explanation for this behavior. Thus, chloride nicely fits inside the cage cavity, while fluoride is too small and the interaction is too loose, being the cavity of the receptor occupied by a water molecule in the crystal structure. On the other hand, bromide is too large leading to a large structural distortion of the cage upon binding with a concomitant energetic penalty. These cages showed to efficiently transport chloride anion through model lipid bilayers, but the chloride transport rate does not correlate with the binding affinity and other physicochemical properties, like hydrophobicity, play an important role in the process. The high modularity in the design of these cages makes them the ideal candidates to use them in structure-activity studies for their potential biological applications. The key role of the appropriate hydrophilic/hydrophobic balance for an efficient transport of chloride has been also shown in different amphiphilic pseudopeptidic systems.[76]

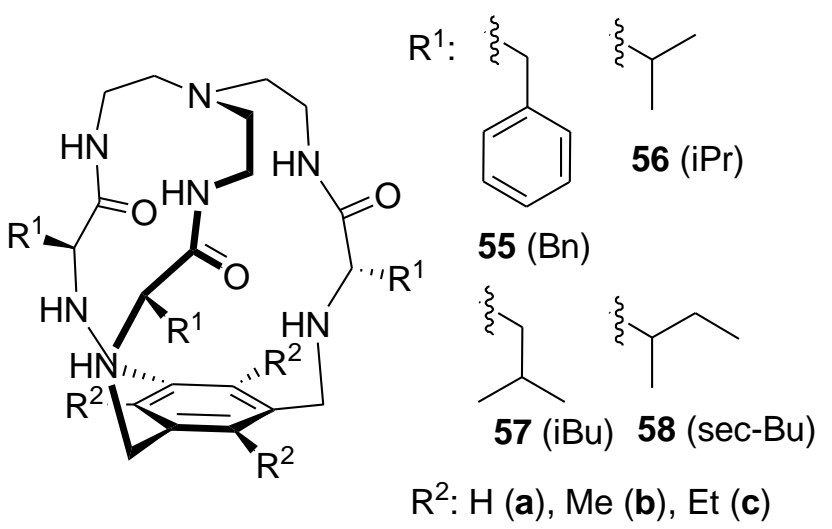

Figure 21. Pseudopeptidic cages able to bind and transport chloride anion through lipid bilayers.

\section{POTENTIAL BIOMEDICAL APPLICATIONS OF PSEUDOPEPTIDES}

4.1. Molecular recognition of biologically important cations.

Copper is an element with dual behavior: when bound to redox proteins, it is essential for many vital processes; in its free form, it is very toxic even at low concentrations. [77] For example, Wilson's disease is a major genetic disorder of copper metabolism[78]: failure of the copper transport in hepatocytes results in accumulation of this metal especially in kidneys, brain and eyes. Copper is also involved in neurodegenerative pathologies such as Alzheimer's disease and is believed to cause $B$ amyloid precipitation.[79]

A potential treatment for these disorders involves the use of molecules able to efficiently and selectively bind $\mathrm{Cu}(\mathrm{I})$, the predominat oxidation state of $\mathrm{Cu}$ in cells, [80] in what is called chelation therapy. Indeed, when copper concentration exceeds physiological requirements, cells induce the biosynthesis of small cysteine-rich proteins, like Metallothioneins (MTs), which are able to complex $\mathrm{Cu}(\mathrm{I})$ forming clusters.

Inspired by the structure of these natural copper carriers, the group of Delangle reported on a series of efficient and selective copper chelators. The first one is a $C_{3}$-symmetric ligand with a nitrilotriacetic acid (NTA) core and three converging metal-binding cysteine-derived chains: 59 (Figure 22).[81]<smiles>CCOC(=O)[C@@H](CS)NC(=O)CN(CC(=O)N[C@@H](CS)C(=O)OCC)CC(=O)N[C@@H](CS)C(=O)OCC</smiles>

Figure 22. Tris(cysteine)-derived ligand for copper (I) cation.

The binding of $\mathrm{Cu}(\mathrm{I})$ to the tris(cysteine) pseudopeptide ligand 59 in aqueous solution was investigated by different techniques. A complex behavior was observed: at low $\mathrm{Cu}(\mathrm{I})$ concentrations, the $C_{3}$-symmetric mononuclear complex Cu59 is formed, in which the ligand wraps the $\mathrm{Cu}(\mathrm{I})$ cation with the three thiolate arms. At higher concentrations, Cu59 was transformed into a cluster complex, $\left(\mathrm{Cu}_{2} \mathbf{5 9}\right)_{3}$. This cluster has a $\mathrm{Cu}_{6} \mathrm{~S}_{9}$ core, as described in some MTs, where each $\mathrm{Cu}(\mathrm{I})$ adopts a nearly trigonal planar coordination. Both the first (leading to $\mathrm{Cu59}$ ) and the second $\mathrm{Cu}(\mathrm{I})$ ion (leading to $\mathrm{Cu}_{6} \mathbf{5 9}_{3}$ ) are very tightly bound as demonstrated by the large value of the binding constants, determined by UV-vis titrations. The high affinity of $\mathbf{5 9}$ for $\mathrm{Cu}(\mathrm{I})$, higher than that of the Met-xCys-X-X-Cys sequence found in natural copper transporters, can be ascribed to the preorganization of the tripodal ligand, which provides three converging metal-binding thiolates.

The selectivity of $\mathbf{5 9}$ for $\mathrm{Cu}(\mathrm{I})$ was assessed by UV-vis titrations; the apparent stability constants of the mononuclear complexes M59 in water follow the order: $\mathrm{Ca}$ (II) $<<\mathrm{Pb}$ (II) $\approx$ $\mathrm{Zn}$ (II) $<\mathrm{Cd}(\mathrm{II})<\mathrm{Cu}$ (I) $<\mathrm{Hg}$ (II). In particular, the selectivity for $\mathrm{Cu}(\mathrm{I})$ over $\mathrm{Zn}(\mathrm{II})$, a potential competitor in cells, is very high $\left(\sim 10^{9}\right)$ and resembles that of metallothioneins and other cysteine-rich proteins.

Later, the same group described a molecule able to both bind intracellular copper and target hepatocytes, by decorating a cyclodecapeptidic scaffold with a chelating unit and a carbohydrate recognition moiety [82]. One face of the cyclopeptide displays four units of $\mathrm{N}$-acetylgalactosamine (GalNAc) to obtain an efficient recognition of the asialoglycoprotein receptor (ASGP-R) which is expressed on the surface of hepatocytes only. The other face, designed for $\mathrm{Cu}(\mathrm{I})$ ion binding, bears the thiolate groups of two cysteines, masked in a disulfide bridge. The macrocyclic glycopeptide 60 (Figure 23) is stable in the presence of oxygen and is not a copper chelating agent per se, whereas once reduced by glutathione (mimicking the intracellular reducing environment), it becomes able to bind $\mathrm{Cu}(\mathrm{I})$ ions.

A fluorescent analogue of $\mathbf{6 0}$ was obtained by functionalization with tetramethylrhodamine isothiocyanate, 
(TRITC); its uptake by various hepatic cell lines proved the efficiency of the targeting unit. Fluorescence microscopy showed that 60-TRITC was able to enter WIF-B9 cells within 2 hours, to accumulate, and to reach the bile canaliculi within a few hours. Moreover, the intracellular localization in the Golgi network of the copper-transporting ATPase ATP7B (a protein responsible for copper detoxification), indicates the disappearance of excess intracellular copper in the presence of $\mathbf{6 0}$, thereby demonstrating its ability to lower intracellular copper concentration. The glycocyclopeptide $\mathbf{6 0}$ can thus be considered as a prodrug activated in the reductive medium of the targeted cells to chelate excess $\mathrm{Cu}(\mathrm{I})$

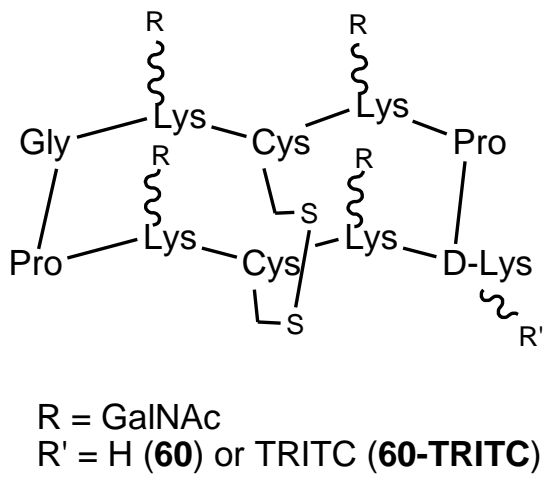

Figure 23. Receptors of copper ion, able to target hepatocytes.

The high selectivity of $\mathbf{6 0}$ for $\mathrm{Cu}(\mathrm{I})$ with respect to $\mathrm{Zn}(\mathrm{II})$ is another important feature, as it allows binding $\mathrm{Cu}(\mathrm{I})$ without perturbing $\mathrm{Zn}(\mathrm{II})$ homeostasis. In addition, since $\mathbf{6 0}$ has a high affinity for the toxic ion $\mathrm{Hg}$ (II), it may also be used as a remedy for mercury-related diseases.

Continuing in this research line, the same group reported on the glycoconjugate $\mathbf{6 1}$ (Figure 24), which is derived from ligand 59 by tethering to each chelating thiolate one GalNAc amino sugar through a disulfide bond. [83] This modification on one hand directs the molecule towards hepatocytes and on the other protects the thiolate functions until they are cleaved in the reducing intracellular medium. Therefore, glycoconjugate $\mathbf{6 1}$ acquires its specificity for $\mathrm{Cu}(\mathrm{I})$ chelation by entering hepatocyte cells.

As evidenced by UV-vis titrations, $\mathbf{6 1}$ does not bind $\mathrm{Cu}(\mathrm{I})$ as it does not contain free thiolate functions. However, when Glutathione (GSH, a mimic of the reducing intracellular environment) was added to the mixture, $\mathrm{Cu}(\mathrm{I})$ was complexed by the high-affinity chelator $\mathbf{5 9}$, obtained after reduction of the disulfide bridges of $\mathbf{6 1}$.

The efficiency of $\mathbf{6 1}$ was tested in two hepatic cell lines. The fluorescent analogue 61-TAMRA, bearing a carboxytetramethylrhodamine unit, was synthesized to visualize the uptake into hepatocytes. In less than two hours 61-TAMRA enters HepG2 cells, a commonly used human hepatic cell line, and WIF-B9 cells, a model for hepatocyte polarity. On the other hand, 61-TAMRA does not enter HeLa cells, lacking ASGP-R, demonstrating in this way the role of the hepatic receptor in the cellular uptake of the glycoconjugate. As seen before, the localization of the ATPase ATP7B can be used as an intracellular copper sensor.
In fact, an immunofluorescence study showed that in basal conditions (low copper concentration), ATP7B stays in the Golgi network, while with added copper ions in the medium (higher concentrations), ATP7B is mainly localized around the canaliculi to excrete the excess of copper into the bile. When WIF-B9 cells were incubated with added copper ions and 61, ATP7B was localized mainly in the Golgi network, thus indicating the ability of reduced $\mathbf{6 1}$ to chelate excess intracellular copper. When cells were incubated with different control compounds, lacking either the carbohydrate units or the copper binding groups, ATP7B was localized in the pericanalicular region, demonstrating that both functions are essential to promote the release of a high-affinity intracellular $\mathrm{Cu}(\mathrm{I})$ chelator once it is in hepatic cells.

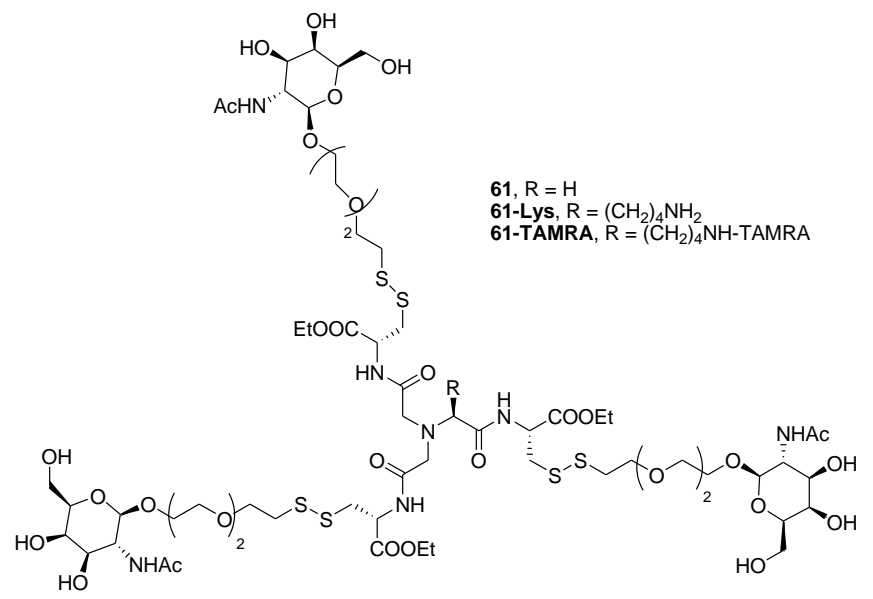

Figure 24. Prochelator for copper, released and activated in the hepatic cells.

Therefore, glycoconjugate $\mathbf{6 1}$ can be considered as a vector delivering 59, the active compound, at the right place to chelate excess $\mathrm{Cu}(\mathrm{I})$ and represents a starting point for a prodrug for the Wilson's disease.

In the pseudopeptidic ligands $\mathbf{5 9}$ and $\mathbf{6 0}$ the copper ion is bound to the thiolate functions of the Cys residues, while the peptidic backbone is not involved in the metal coordination. In other cases, the metal ion is directly bound to the amide functions. García-España and Luis reported on the $\mathrm{Cu}(\mathrm{II})$ and $\mathrm{Zn}$ (II) coordination properties of a family of pseudopeptidic ligands (62a-e, Figure 25) with $C_{2}$ symmetry in which two valine residues are linked by a central aliphatic spacer of different length.[84]

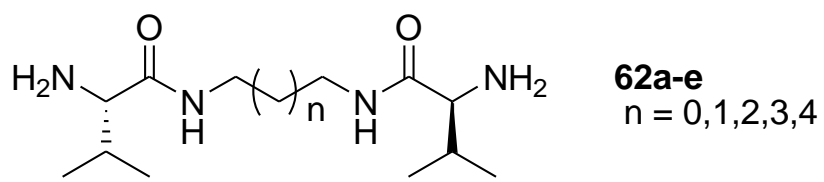

Figure 25. Pseudopeptidic ligands for $\mathrm{Cu}(\mathrm{II})$ and $\mathrm{Zn}(\mathrm{II})$ metal ions.

The metal binding in aqueous solutions was studied by potentiometric titrations and Uv-vis spectroscopy, and the results were confirmed by mass spectrometry. In all cases, the 
$\mathrm{Cu}$ (II) complexes are much more stable than the $\mathrm{Zn}$ (II) complexes (about three orders of magnitude). Potentiometry titrations showed that bis-deprotonated mononuclear complexes are the only species formed for $\mathrm{Zn}$ (II) and the most abundant ones for $\mathrm{Cu}$ (II). In these complexes the metal ion displays square planar coordination geometry, being bound to two amine groups and two deprotonated amide groups. In fact, the color of the copper complexes ranges from red to purple $(\lambda \max =490-560 \mathrm{~nm})$, due to d-d transitions typical of the copper ion with square-planar or square-pyramidal geometry. This geometry was found also in the solid state, in the crystal structure of the bis-deprotonated Cu62b complex. Zinc complexes are colorless, but the shifts of the carbonyl frequency (FT-IR) from $1663 \mathrm{~cm}^{-1}$ in free ligands to $1566 \mathrm{~cm}^{-}$ 1 in metal complexes indicate the participation of the deprotonated amide group in the metal coordination.

In the case of $\mathrm{Cu}(\mathrm{II})$, the coordination patterns are more complex and not limited to bis-deprotonated mononuclear complexes. Different complexes with 1:1 or $2: 2 \mathrm{Cu}(\mathrm{II}): \mathrm{L}$ stoichiometries can be formed according to the length of the spacer and the basicity of the media. For example, the resolution of the $\mathrm{X}$-ray structure of the $\mathrm{Cu}$ (II) complex with 62a ligand revealed a binuclear complex, $\left[\mathrm{CuH}_{-1} \mathbf{6 2} \mathbf{a}\right]_{2}$ in which every copper ion is coordinated to two amino groups and two amido oxygen atoms, maintaining the square planar geometry.

Faggi and Alfonso described the copper coordination displayed in methanol by pseudopeptidic ligands derived from phenylalanine (Figure 26).[85] Open-chain bis(amino amide) ligands 63 and 64 formed mononuclear $\mathrm{Cu}(\mathrm{II})$ complexes, while macrocyclic tetra-(amino amide) ligands 65 and 66 formed dinuclear $\mathrm{Cu}$ (II) complexes. As indicated by EPR and Uv-vis spectra, the metal ion always displays the square planar coordination geometry, being connected to four nitrogen atoms (two amines and two deprotonated amides). In fact, all complexes are purple, with $\lambda$ max in the 498-526 nm range, and EPR parameters typical of neutral $\mathrm{CuN}_{4}$ units. The crystal structure of the Cu64 complex confirmed the coordination sphere of the $\mathrm{Cu}(\mathrm{II})$ ion.

As highlighted by UV-vis and EPR studies, the complexes interact with hydroxy- and amino-dicarboxylate substrates, being insensitive to other dicaboxylates such as succinate or $\mathrm{N}$-acetyl-aspartate. The titration of the corresponding $\mathrm{Cu}$ (II) complexes with aspartate, glutamate or malate decreased the absorption band around $500 \mathrm{~nm}$, while a broader and less intense band at $620-650 \mathrm{~nm}$ grew. Concomitantly, EPR parameters showed a change from $\mathrm{CuN}_{4}$ to $\mathrm{CuN}_{2} \mathrm{O}_{2}$ units. No important differences were observed between mononuclear and binuclear complexes. The behavior of $\mathrm{Cu} 63$ was studied in detail, revealing a completely different outcome for the interaction with two biologically important dicarboxylates possessing very similar structures (malate and aspartate). In the case of malate, a ternary complex [ligand $\cdots$ metal $\cdots$ dicarboxylate] is formed almost quantitatively; while in the case of aspartate, the anion is able to displace $\mathrm{Cu}(\mathrm{II})$ from the ligand to form, mainly, the $\mathrm{Cu}(\mathrm{Asp})_{2}$ complex. Cu63-66 are model compounds that mimic the ligand exchange observed in natural systems and especially the function of metal ionophores. In fact, ionophores are specific ligands that bind a metal cation, transport it across a cellular membrane, and then release it in response to different stimuli (for example lower $\mathrm{pH}$ or presence of competitive ligands). The major drawback of these systems is their low solubility in water, which could be overcome by replacing phenylalanine with a more molar aminoacidic residue.
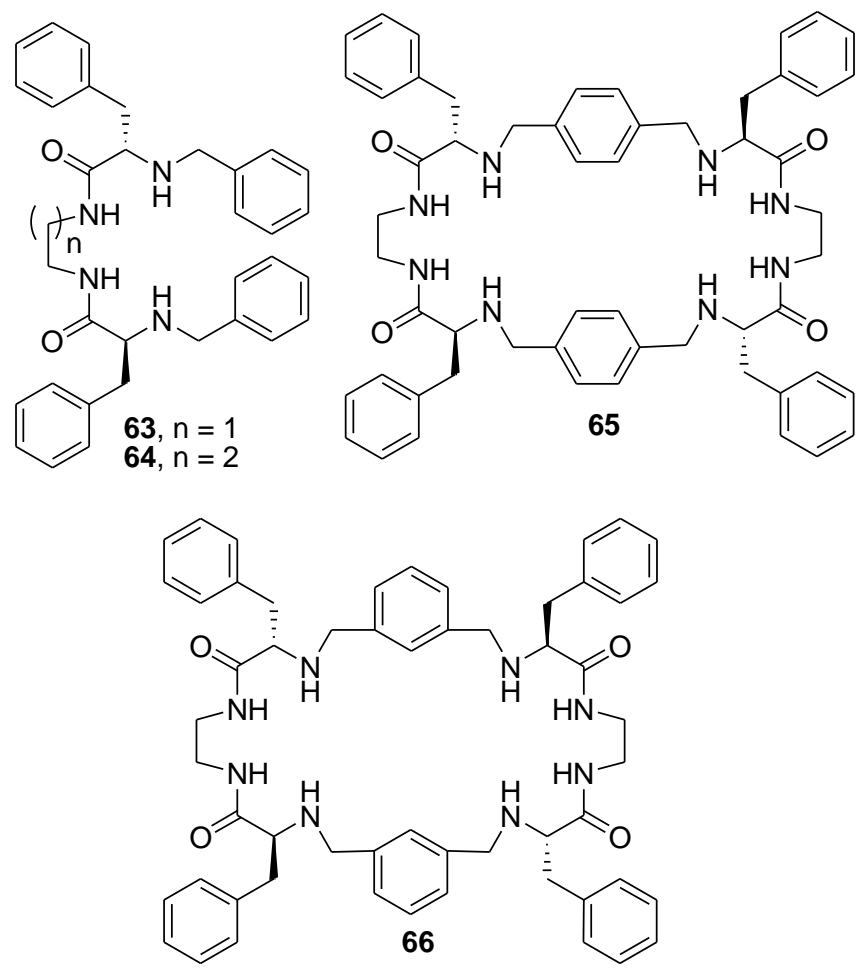

Figure 26. Open-chain and macrocyclic receptors of $\mathrm{Cu}$ (II) ion that are able to interact with biologically important dicarboxylates.

\subsection{Molecular recognition of biologically relevant anions}

The biological importance of many anions has driven the development of artificial anion receptors, nowadays an important area of research in supramolecular chemistry. Artificial receptors in which the substrate is bound by hydrogen bonds as in natural systems are, however, often only effective in nonpolar solvents. For complexation in water, due to the high solvation energy of many anions, stronger interactions are usually needed, such as electrostatic or coordinative bonds. Kubik et al. reported on the cyclic pseudopeptide 67 (Figure 27), containing L-proline and 6aminopicolinic acid subunits in an alternating sequence, and able to bind anions such as halides and sulfates through hydrogen bonds in aqueous solutions. [86]

The anions are held in the cavity that results from the pairing of two pseudopeptide molecules. According to X-ray crystal structure analysis, 67 displays $C_{3}$ symmetry, with the protons of the $\mathrm{NH}$ groups arranged on the same side as the nitrogen atoms of the pyridine rings. Upon the addition of one equivalent of several anions to a solution of $\mathbf{6 7}$ in $d_{6}$-DMSO, downfield shifts are observed for the NMR signals of the $\mathrm{NH}$ 
protons, indicating their involvement in hydrogen bonds to the anions. The same shifts were observed in $d_{6}$-DMSO : $\mathrm{D}_{2} \mathrm{O}$ mixtures, up to $80 \% \mathrm{D}_{2} \mathrm{O}$ (the low solubility of $\mathbf{6 7}$ prevented its study in pure water). Interaction of 67 was proved with chloride, bromide, iodide, sulfate, benzenesulfonate, and carbonate in $4: 1 \mathrm{D}_{2} \mathrm{O}: \mathrm{CD}_{3} \mathrm{OD}$. Job plots revealed a $2: 1$ receptor : substrate stoichiometry, which was confirmed by ESI-MS spectrometry. From the intensity of the peaks the stability order of the three halide-complexes was inferred: $\mathrm{Cl}^{-}$ $<\mathrm{Br}^{-}<\mathrm{I}^{-}$. In the crystal structure of the corresponding complex the iodide anion is located in a cavity between two cyclopeptide molecules, which engage perfectly, with corresponding planes of two pyridyl-carbonyl-proline units coming together in close contact. Six NH groups point into the cavity and bind the enclosed anion through hydrogen bonds, with an approximately trigonal prismatic coordination geometry of the iodide anion.
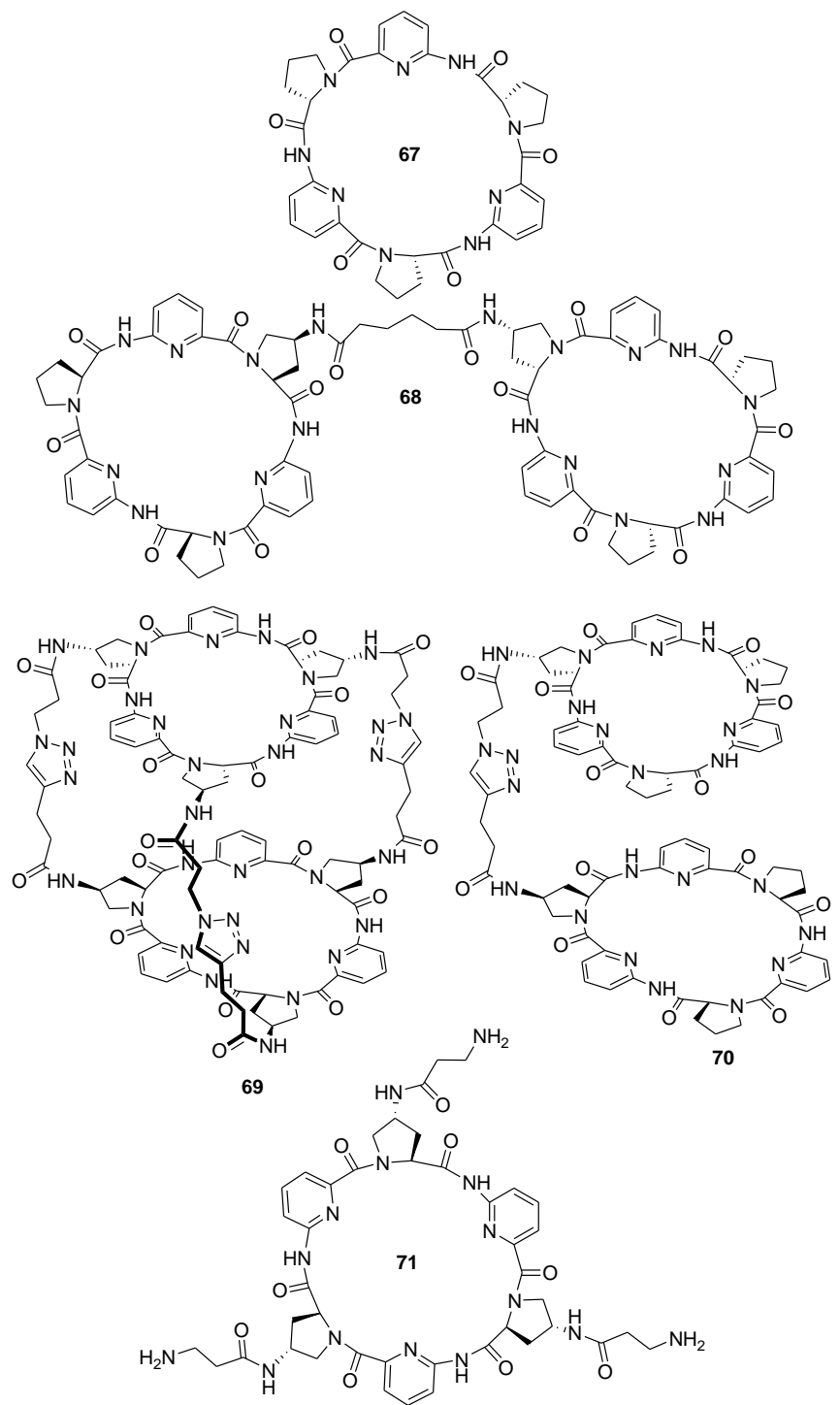

Figure 27. Macocyclic and macrobicyclic receptors described by Kubik and co-workers.

As an extension of this work, receptor 68 was prepared, in which two units of receptor $\mathbf{6 7}$ are covalently connected via an adipic acid spacer (Figure 27).[87] This compound was designed to stabilize the $2: 1$ sandwich-type anion complexes that are observed with receptor 67 and to obtain a $1: 1$ stoichiometry. ESI-MS and NMR studies showed that the bridged bis(cyclopeptide) $\mathbf{6 8}$ forms $1: 1$ complexes with halides, sulfate, and nitrate. The stabilities of the anion complexes were determined by NMR and microcalorimetry titrations in $1: 1$ water : methanol mixtures. Both techniques provided the stability order $\mathrm{SO}_{4}{ }^{2-}>\mathrm{I}^{-}>\mathrm{Br}^{-}>\mathrm{Cl}^{-}>\mathrm{NO}_{3}{ }^{-}$(with stability constants in the range $10^{5}-10^{2} \mathrm{M}^{-1}$. Larger anions form more stable complexes because they better fit into the cavity of the host. In addition, sulfate forms stronger hydrogen bonds to the $\mathrm{NH}$ groups of the receptor.

With the aim of further improving the binding of cyclic pseudopeptidic receptors towards anions, the same group developed other two analogues of the original receptor 67, namely 69 and 70. Receptor 69 is composed of two pseudopeptidic rings connected by a triazole-containing arm, with the same bis-macrocyclic structure of 68 . In receptor $\mathbf{7 0}$, the two pseudopeptidic rings are triply connected, again by triazole-containing arms, affording a much more preorganized molecular cage (Figure 27). As seen in the case of 68, receptors 69 and 70 form sandwich-type complexes between the cyclopeptide rings and inorganic anions with 1 : 1 stoichiometry, in aqueous solution.[88]

Kinetically, the triply linked system differs significantly from the bis-cyclopeptide that contains only one linker, because the rate of guest exchange is considerably slower, as observed in NMR spectra (separate signals for free and complexed 70). Thermodynamically, the stability of the sulfate complex of the triply linked bis-cyclopeptide approaches a $\log K_{\mathrm{a}}$ value of 6 in $1: 1$ water : methanol mixture, only one order of magnitude larger than affinity of the more flexible monolinked analogue 69. Calorimetry titrations revealed that this behavior is mainly due to the change in the binding enthalpy from exothermic to endothermic upon increasing the number of linkers. Results from NMR spectroscopy and X-ray crystallography indicated that the mono- and triply linked bis-cyclopeptides adopt similar conformations in their complexes with sulfate ions, but the complex formation is enthalpically unfavorable for the cage. This can be due to three main reasons: inefficient approaching of the two cyclopeptide rings, energetically unfavorable linker conformations, and higher energy required for desolvation of the binding sites.

However, the large entropic contribution to sulfate complexation of receptor $\mathbf{7 0}$ more than compensates for the entropic disadvantage, so that the overall sulfate affinity of receptors 69 and 70 ends up in the same range.

Selective recognition of sulfate ion in water has been achieved by the same group using a cyclopeptide containing aminopicolinic acid residues alternating with (4R)-4aminoproline subunits with appended $\beta$-alanine residues (receptor 71, Figure 27).[89] Compound 71 showed a high affinity and selectivity for sulfate in aqueous solution even in the presence of competing anions such as $\mathrm{AcO}^{-}, \mathrm{Cl}^{-}, \mathrm{HPO}_{4}{ }^{2-}$ or $\mathrm{H}_{2} \mathrm{PO}_{4}$. The ability of $\mathbf{7 1}$ to discriminate between sulfate and phosphate, two tetrahedral oxanions of similar ionic radius, arises by a combination of electrostatic interactions 
(ammonium groups of $\beta$-alanine) and hydrogen bonds (NH groups along the ring, converging toward the center) that results in a perfect wrapping of the guest. This binding mode is suggested by mass spectrometry, ${ }^{1} \mathrm{H}$ NMR spectroscopy and ITC analyses, as well as by the calculated structure of the sulfate complex of $\mathbf{7 1} \cdot 3 \mathrm{H}^{+}$.

For further examples of macrocyclic pseudopeptides as anion receptors, the reader can consult the excellent review by Elmes and Jolliffe.[90]

\subsection{Molecular recognition of amino acids, dipeptides and polypeptides}

Alfonso and Luis reported on the binding between the pseudopeptidic macrocyclic naphthalenophane 18 (Figure 6), including valine residues, and several $\mathrm{N}$-protected amino acid derivatives in dichloromethane and chloroform.[91] NMR titrations allowed the characterization of the intermolecular interactions, and revealed a slight side chain and Lstereoselectivity of the host-guest complexes. The data suggested the formation of a tight ionic pair, formed by the proton transfer from the carboxylic guest to the amino macrocycle. Presence of additional intermolecular interactions like H-bonding and $\pi-\pi$ contacts is also envisaged, as $\mathbf{1 8}$ shows a stronger interaction with substrates bearing aromatic rings, either in the side chain (phenylalanine, phenylglycine) or in the amino-protecting group (Cbz). Receptor 18 alone displays an emission band at 390, due to a photoinduced electron transfer (PeT) between the secondary amines and the first excited singlet state of the naphthalene moiety, leading to an emissive exciplex. In absence of this PeT mechanism, for example when the amine nitrogens are protonated, the typical fluorescence of the naphthalene fluorophore, at $340 \mathrm{~nm}$, is observed. Fluorescence titrations of 18 with aromatic amino acid derivatives (Z-L-Phe-OH and ZD-Phe-OH) showed quenching of the emission at $390 \mathrm{~nm}$ accompanied by recovering of the emission at $340 \mathrm{~nm}$, highlighting the formation of ionic pairs and consequent loss of PeT process. On the other hand, fluorescence titrations with aliphatic amino acid derivatives (Z-Ala-OH, Z-Val-OH, ZLeu-OH) afforded slight changes in the emission, as result of a weaker interaction. Binding constants and other thermodynamic parameters, together with ROESY measurements, allowed to propose a structure for the supramolecular complexes, in which the interactions of the naphthyl ring strongly influence the strength and selectivity of the molecular recognition.

As an extension of this work, the binding of four larger pseudopeptidic macrocycles derived from valine and phenylalanine (Figure 28) with N-protected amino acids and N-protected dipeptides was studied by means of ESI-MS and NMR spectroscopy.[92] Competition ESI-MS experiments were employed for the screening of the supramolecular complexes formed by the macrocycles and seven different peptide-like substrates. Receptor 72 (bearing cyclohexane spacers and $i$-Pr side chains) stood out as the best receptor, also showing stronger binding with $\mathrm{N}$-protected dipeptides over simple N-protected amino acids (size selectivity).
Among the dipeptides studied, $\mathbf{7 2}$ displayed a slight preference towards aromatic containing dipeptides (sequence or side chain selectivity). The intrinsic stabilities of the supramolecular complexes in the gas phase were additionally studied by Collision Induced Dissociation (CID) ESI-MS experiments, confirming this preference. NMR titrations in chloroform provided stability constants for the host-guest complexes: $\mathbf{7 2}$ formed slightly stronger host-guest complexes than $\mathbf{7 3}$ (bearing ethylene spacers), while the stability trend (Z-AA-OH $<$ Z-AF-OH $<$ Z-FF-OH) was further confirmed. High resolution NMR experiments (NOESY, DOSY) on the most soluble complex [72.Z-AF-OH] together with the data from titrations and with the help of molecular modeling suggested a model for the host-guest complex in which the dipeptide is located on top of the macrocyclic cavity and aligned with the phenylene groups, setting the central part of the substrate close to the aromatic rings of the host.

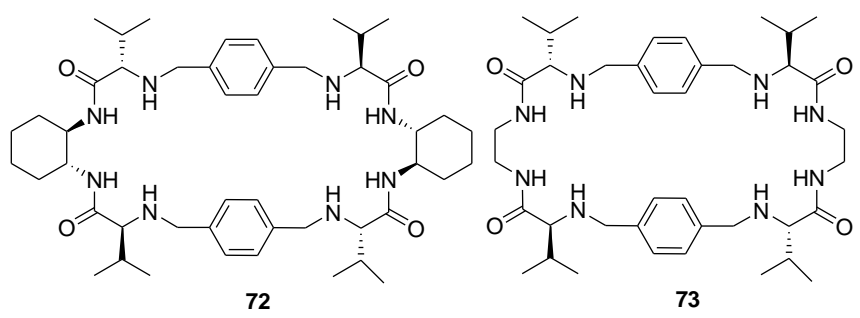

Figure 28. Macrocyclic pseudopeptides as receptors for Nprotected dipeptides.

The understanding and the control of peptide-peptide noncovalent interactions are major challenges in supramolecular and biological chemistry. Therefore, the results reported in the last two studies are surely interesting. However, it has to be noted that the strength and selectivity of the binding are moderate, and the process has been studied in noncompetitive solvents.

Pseudopeptidic molecular cages (or macrobicycles) were developed by the same group in order to obtain more effective and selective receptors for peptide-like substrates. In principle, the three-dimensional structure of the cages should display more efficient recognition of these challenging substrates through a well-defined network of noncovalent bonds. A small family of molecular cages (Figure 29) was prepared, varying the amino acid residues (Val, Ser, Phe) and the spacers (chx, et, pr). The cage hosts were assayed for dipeptide binding using competition ESI-MS experiments as high-throughput screening to obtain general trends for the recognition phenomena.[93]

Receptor 74, containing serine residues and cyclohexanediamine spacers, showed the best binding abilities, followed by $\mathbf{7 5}$ (valine residues and cyclohexanediamine spacers), while more flexible receptors, constructed with ethylenediamine or propylenediamine spacers, were less efficient. Regarding substrate-selectivity, the Ac-EF-OH and Ac-EY-OH sequences were identified as the most specific for the host 74. Selected hosts were additionally studied by NMR spectroscopy $\left({ }^{1} \mathrm{H}\right.$ NMR titration and diffusion-ordered spectroscopy experiments) in solvents of different polarity, including the highly competitive $2: 1$ 
$\mathrm{CD}_{3} \mathrm{CN}: \mathrm{CD}_{3} \mathrm{OH}$ mixture. The results rendered quantitative information about the strength of the interaction $\left(K_{\text {ass }}\right)$. The cages showed a remarkable selectivity for $\mathrm{N}$-protected dipeptides with an aromatic amino acid at the $\mathrm{C}$ - terminus and an acetyl group at the $\mathrm{N}$-terminus, with the highest stability constant found for receptor 74 - Ac-EY-OH system. Ac-EY$\mathrm{OH}$ mimics a biologically relevant target sequence for kinase enzymes.

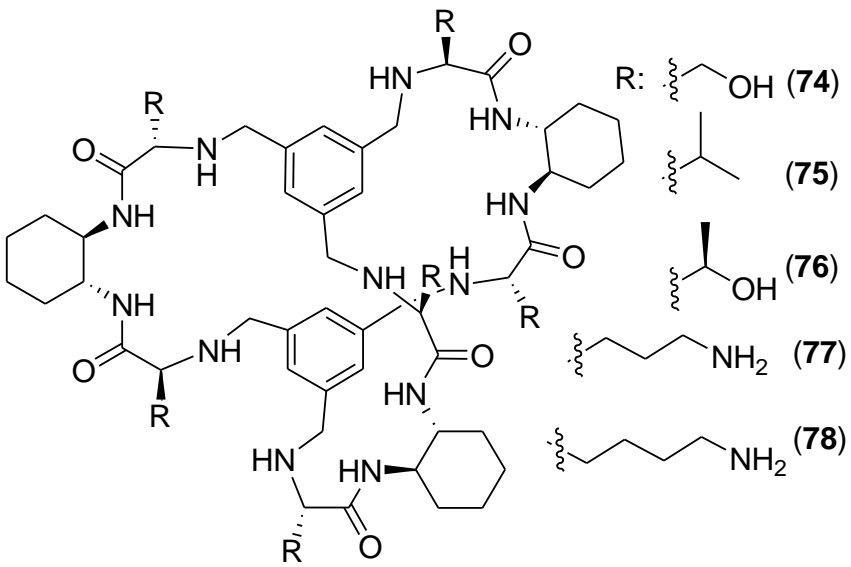

Figure 29. Pseudopeptidic cages able to recognize specific peptide sequences containing aromatic (mainly Tyr) side chains.

The pseudopeptidic molecular cages were characterized also by fluorescence spectroscopy. A model of interaction, obtained by molecular mechanics calculations, envisages partial inclusion of the Ac-EY-OH guest inside the cavity of receptor 74, with the establishment of many electrostatic and polar intermolecular interactions, as well as $\pi-\pi$ stacking between aromatic rings. This model is based on the combination of non-covalent interactions that are configurationally dependent and thus, they could cooperatively work in exerting stereoselective recognition. To prove this hypothesis, the authors tested the previously reported 74 and the corresponding threonine counterpart (76) in a molecular recognition study towards the four possible stereoisomers of Ac-Glu-Tyr-OH dipeptide.[94] Meticulous NMR titrations in aqueous acetonitrile provided the binding constants and highlighted a difference in the stability of the corresponding diastereomeric host-guest complexes. The Serine cage $\mathbf{7 4}$ proved to be slightly more efficient than the Threonine cage 76, although both showed similar stereoselectivity trends: $\mathrm{LL}>\mathrm{DD} \approx \mathrm{LD}>\mathrm{DL}$. Interestingly, the stability of the interaction remains practically unaffected by the amount of water present in the solvent, pointing out that the microenvironment of the receptor is very similar regardless of the overall amount of water, since this host would show a very efficient hydration sphere. The binding process is stereoselective also in the gas phase, as shown by ESI-MS competition experiments using the enantiomerlabelled method (EL), as well as CID experiments. The selectivity trends determined by MS are very similar to those observed by NMR, suggesting that the stereoselectivity observed for these systems is mainly due to the polar hostguest interactions.
The tyrosine residue in proteins is a biologically interesting target: for instance, the Glu-Tyr-Glu sequence is a wellknown substrate epitope of protein tyrosine kinases (PTKs),[95] which catalyze the transfer of a phosphoryl group from ATP to the Tyr hydroxyl group. This event is closely connected with cell regulation, signaling and growth. Thus, the abnormal function of PTKs is related to diseases such as diabetes, cancer[96] and neurodegenerative diseases.[97] Therefore, there is a current interest in the development of molecules and mechanisms to modulate kinase activity. It was envisioned that the pseudopeptidic cages with good affinity for the corresponding peptidic substrates would form stable supramolecular complexes, protecting the Tyr residues from the enzymatic phosphorylation.

To maximize the affinity for the Glu-Tyr-Glu sequence, two molecular cages with side chains positively charged at neutral $\mathrm{pH}$ were prepared (77 and 78, Figure 29).[98] The interaction between these two hosts and a series of oligo- and polypeptides containing the Glu-Tyr-Glu sequence was studied in buffered water at $\mathrm{pH} 7.3$ by means of ${ }^{1} \mathrm{H}-\mathrm{NMR}$ and fluorescence titration experiments. Interaction was confirmed in all cases, with dissociation constants ranging from 1170 to $140 \mu \mathrm{M}$, depending on the specific target sequence and on the receptor.

Then, an in vitro assay for the evaluation of the specific activity of tyrosine kinases was used to determine whether the molecular cages affected the phosphorylation reaction. Experiments were performed in the absence and in the presence of the cages at different concentrations, and $\mathbf{7 7}$ and 78 displayed interesting competition with the PTK in the micromolar range. For example, at concentration values around $20 \mu \mathrm{M}, 78$ provoked a $50 \%$ decrease of the enzymatic activity. These results suggest that engaging the substrate in a supramolecular interaction with a synthetic host could be an efficient way of modulating enzyme activity.

\subsection{Pseudopeptides for drug delivery}

The group of Ulijn designed a phenylacetyl pseudopeptide (79, Figure 30) able to undergo a morphological change from micellar aggregates to fibers in response to cleavage by an endopeptidase enzyme (MMP-9), which is overexpressed in certain types of cancer.[99] This compound was used for localized formation of a reservoir for slow release of the hydrophobic anti-cancer drug doxorubicin. Its structure comprises a biocompatible fiber-forming self-assembling unit (phenylacetyl-FFAG) that also provides the hydrophobic binding moiety for the drug, the enzyme cleavable sequence and a hydrophilic unit (LDD) that modifies the amphiphilic balance of the precursor to favor micelle formation. The release of doxorubicin was studied by fluorescence emission spectroscopy. The emission of the doxorubicin-79 ensemble decreased slowly over time suggesting that the drug stays incorporated into micelles, allowing only low release. When treated with the endopeptidase a release from micelles takes place (with a decrease in fluorescence intensity) followed by entrapment into fibers (increase of fluorescence intensity). Although the overall release is similar, the advantage of the 
enzymatic approach is the spatial control of the release, as the endopeptidase is overexpressed in certain types of cells (for example tumor tissues).

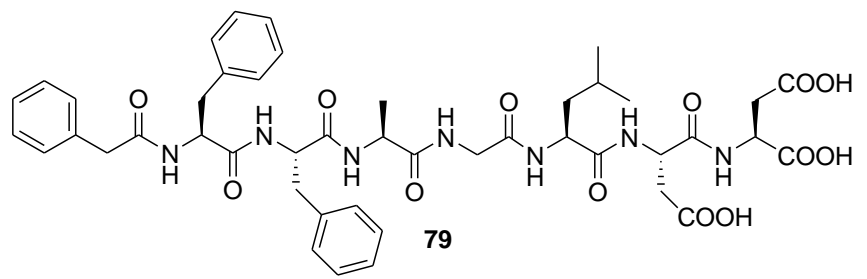

Figure 30. Fiber-forming pseudopeptide for drug delivery of doxorubicin anticancer drug.

\section{5. Pseudopeptidic molecules as gene transfection agents}

Gene therapies rely on the efficient delivery of nucleic acids into cells. DNA cannot penetrate directly through cell membranes and requires a transport mechanism for cellular uptake. Apart from conventional viral carriers, novel classes of vectors are currently in use: cationic lipids and cationic polymers. Both are rather large oligomeric or polymeric compounds, while small molecules have been less investigated.

Schmuck and co-workers reported on several pseudopeptidic gene transfection agents, all bearing a weakly basic guanidiniocarbonyl pyrrole moiety (GCP), an efficient arginine analogue (80-85, Figure 31). The small, three-armed peptide ligand 80, derived from the cationic dipeptide LysPhe with a GCP moiety at its N-terminus, binds to DNA with high affinity $\left(K_{\mathrm{a}} \approx 10^{7} \mathrm{M}^{-1}\right)$ and efficiently delivers a green fluorescent protein (GFP) plasmid into cells.[100]

Compared to the cationic polymer polyethyleneimine (PEI), used as a standard vector for transfection, 80 is significantly more efficient and also less cytotoxic. Dynamic light scattering and atomic force microscopy studies show that ligand $\mathbf{8 0}$ condenses DNA into compact cationic aggregates, which are then taken up by the cells. On the other hand, the analogous divalent pseudopeptide ligand $\mathbf{8 1}$ of identical amino acid sequence and the highly charged divalent DNAbinder 82 (Lys-Lys-Arg) are not able to deliver genetic material although they also bind DNA with high affinity (81: $K a \approx 10^{6} \mathrm{M}^{-1} ; 82: K a \approx 10^{7} \mathrm{M}^{-1}$ ). The reason of this different behavior lies in the ability of the trivalent gene carrier to escape from the endosome, due to its superior buffering capacity. The comparison shows the importance of the GCP group, responsible for both the binding of the nucleic acids and their release from the endosome by acting as a proton sponge. The same research group introduced the GCP moiety into the side chains of tetralysine to obtain the pseudopeptide 83.[101] This modification probably enhances the transfection efficacy through more specific interaction between the binding motifs and DNA or the cell membrane. Tetrapeptide $\mathbf{8 3}$ was compared to tetralysine and tetraarginine peptides, and while the three compounds show very similar binding affinities towards DNA, their transfection abilities are strikingly different. In fact, while tetralysine and tetraarginine do not lead to any detectable transfection, 83 allows successful transfection of HeLa cells with a plasmid encoding green fluorescent protein.<smiles>[R7]NCc1cc(CN[R7])cc(CN[R1])c1</smiles><smiles>NCc1cc(CNP)cc(C(=O)NCC(N)=O)c1</smiles><smiles>N=C(N)NC(=O)c1ccc(C(=O)NC(CCCCN)C(=O)NC(Cc2ccccc2)C(=O)PBr)[nH]1</smiles><smiles>[R7]CC(=O)C(CCCCN)NC(=O)C(CCCCN)NC(=O)C(CCCNC(=N)N)NC(=O)c1ccc(C(=O)NC(N)=NC(=N)N)[nH]1</smiles>

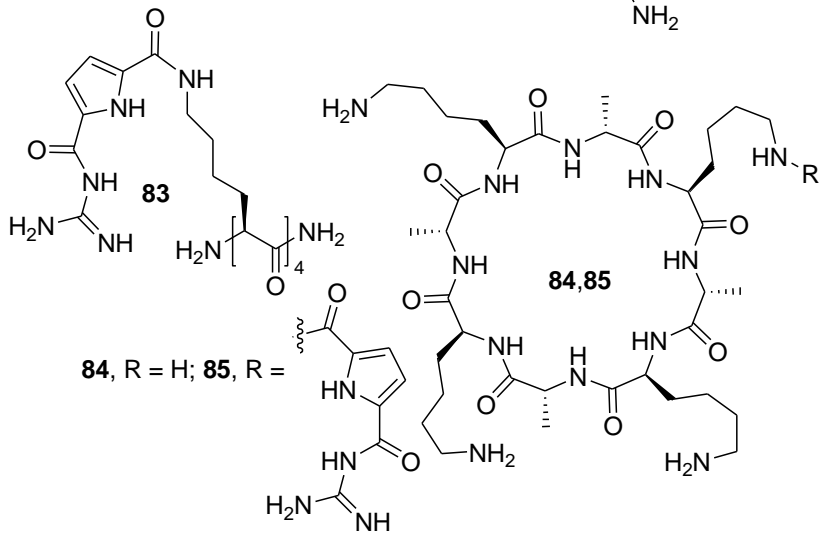

Figure 31. Pseudopeptides for gene transfection developed by Schmuck and co-workers.

The same group described also how the functionalization of a tetracationic cyclic octapeptide with a single guanidiniocarbonyl pyrrole (GCP) moiety, alters dramatically the self-assembly properties of the pseudopeptide. While the non-functionalized compound $\mathbf{8 4}$ does not self-assemble, GCP-containing pseudopeptide $\mathbf{8 5}$ forms cationic nanorods of micrometer length, as observed by both atomic force microscopy and transmission electron microscopy studies. Molecular modelling suggests that the GCP group could stabilize a stack of pseudopeptides by binding to the backbone of an adjacent cyclic peptide, working as a clamp between the stacked cyclic peptides and reducing the electrostatic repulsion between lysine residues. Negatively charged DNA binds to the cationic pseudopeptide nanorods, as evidenced in TEM images. These aggregates are efficient gene transfection vectors, being able to transport the green fluorescent protein plasmid into HeLa cells. The transfection, based on the binding of DNA to the cationic surface of the pseudopeptide nanotubes, was also confirmed in human embryonic kidney cells.[102] 
Kelley and co-workers reported on methotrexatecontaining pseudopeptides, 86 and 87 (Figure 32), as antimicrobial delivery vectors for the intracellular removal of the Listeria monocytogenes pathogen from mammalian cells.[103]<smiles>CN(CCC[C@H](NC(=O)[C@H](CC1CCCCC1)NC(=O)CC[C@H](NC(=O)c1ccc(N(C)Cc2cnc3nc(N)nc(N)c3n2)cc1)C(N)=O)C(=O)O)C(=O)O</smiles><smiles>CC[C@H](NC(=O)[C@H](CCCNC(=N)N)NC(=O)[C@H](CC1CCCCC1)NC(=O)CC[C@H](NC(=O)c1ccc(N(C)Cc2cnc3nc(N)nc(N)c3n2)cc1)C(=O)O)C(=O)N[C@@H](CCNC(=N)N)C(N)=O</smiles>

Figure 32. Methotrexate-containing pseudopeptides for antibacterial activity.

The pseudopeptide $\mathbf{8 6}$ was made up of six amino acids and features alternating hydrophobic (cyclohexylalanine) and cationic (D-arginine) residues apart from the antimicrobial agent. The hydrophobic character of the pseudopeptide allows for efficient penetration of biological membranes, while the cationic residues promote penetration of membranes and localization within the mitocondrial matrix or bacterial cytosol. The latter property was determined by fluorescence microscopy, in a colocalization experiment carried out with an analogue of 86 in which TAMRA fluorophore replaced methotrexane, and commercially available CellTrace Far Red. In vitro, 86 displayed strong growth inhibition towards cultured L. monocytogenes, with a slight increase with respect to the unconjugated methotrexane. Compound $\mathbf{8 6}$ was also tested against Hela cells infected with L. monocytogenes; it maintained the growth inhibitory activity towards the intracellular pathogen, accompanied by low toxicity. In contrast, methotrexane alone showed both growth inhibition and toxicity towards human cells. A modified vector, 87, including six D-arginine residue alternating with three cyclohexylalanine and three methylalanine, showed the interesting property of increased accumulation in bacteria than in mitochondria, a feature that was ascribed to its increased positive charge with similar hydrophobicity.

\section{CONCLUSION}

The design of new molecular tools for biomedical applications in sensing and therapeutic usage is a current challenge in medicinal chemistry. This area of research is usually hampered by synthetic difficulties, undesired physicochemical properties (i.e. aggregation or poor aqueous solubility) or unexpected toxicity. Pseudopeptidic structures are very good platforms for chemical design, since they combine several of the benefits from peptide chemistry and from purely synthetic chemical structures. In this review, the applicability of pseudopeptides as biomedical tools has been discussed, showing a very promising future in both diagnosis and therapy usage. There is still plenty of room for development, since the structural possibilities are almost infinite. Moreover, the acquisition of knowledge in the field will facilitate the tailor-made preparation of new molecules with the desired properties to be used in biomedicine. This allows envisioning a growing development in both the chemical design of new structures and their biologically relevant applications.

\section{CONFLICT OF INTEREST}

The authors declare no conflicts of interest.

\section{ACKNOWLEDGEMENTS}

Financial support from MINECO/FEDER (CTQ201568429-R and CTQ2015-70117-R projects) and Generalitat de Catalunya (AGAUR, 2014 SGR 231) is gratefully acknowledged.

\section{REFERENCES}

[1] Prins, L.J.; Scrimin, P. In Functional Synthetic Receptors; Wiley-VCH Verlag GmbH \& Co. KGaA, 2005, pp $1-43$.

[2] Luis, S.V.; Alfonso, I., Bioinspired Chemistry Based on Minimalistic Pseudopeptides. Accounts of Chemical Research, 2014, 47, (1), 112-124.

[3] Alfonso, I., From simplicity to complex systems with bioinspired pseudopeptides. Chemical Communications, 2016, 52, (2), 239-250.

[4] Celine, A.; Claudio, S., Converting a Peptide into a Drug: Strategies to Improve Stability and Bioavailability. Current Medicinal Chemistry, 2002, 9, (9), 963-978.

[5] Boron, W.F., Regulation of intracellular $\mathrm{pH}$ Advances in Physiology Education, 2004, 28, (4), 160-179.

[6] Casey, J.R.; Grinstein, S.; Orlowski, J., Sensors and regulators of intracellular pH. Nat Rev Mol Cell Biol, 2010, $11,(1), 50-61$.

[7] Han, J.; Burgess, K., Fluorescent Indicators for Intracellular pH. Chemical Reviews, 2010, 110, (5), 27092728. 
[8] Bissell, R.A.; de Silva, A.P.; Gunaratne, H.N.; Lynch, P.M.; Maguire, G.E.; McCoy, C.P.; Sandanayake, K.S. In Photoinduced Electron Transfer V; Springer, 1993, pp 223-264.

[9] Galindo, F.; Burguete, M.I.; Vigara, L.; Luis, S.V.; Kabir, N.; Gavrilovic, J.; Russell, D.A., Synthetic macrocyclic peptidomimetics as tunable $\mathrm{pH}$ probes for the fluorescence imaging of acidic organelles in live cells. Angewandte Chemie - International Edition, 2005, 44, (40), 6504-6508.

[10] Burguete, M.I.; Galindo, F.; Izquierdo, M.A.; O'Connor, J.E.; Herrera, G.; Luis, S.V.; Vigara, L., Synthesis and evaluation of pseudopeptidic fluorescence $\mathrm{pH}$ probes for acidic cellular organelles: In vivo monitoring of bacterial phagocytosis by multiparametric flow cytometry. European Journal of Organic Chemistry, 2010, (31), 5967-5979.

[11] Izquierdo, M.A.; Wadhavane, P.D.; Vigara, L.; Burguete, M.I.; Galindo, F.; Luis, S.V., The interaction of amino acids with macrocyclic $\mathrm{pH}$ probes of pseudopeptidic nature. Photochem Photobiol Sci, 2017.

[12] Faggi, E.; Serra-Vinardell, J.; Pandey, M.D.; Casas, J.; Fabriàs, G.; Luis, S.V.; Alfonso, I., Pseudopeptidic fluorescent on-off $\mathrm{pH}$ sensor based on pyrene excimer emission: Imaging of acidic cellular organelles. Sensors and Actuators, B: Chemical, 2016, 234, 633-640.

[13] Saura, A.V.; Marín, M.J.; Burguete, M.I.; Russell, D.A.; Galindo, F.; Luis, S.V., The synthesis of new fluorescent bichromophoric compounds as ratiometric $\mathrm{pH}$ probes for intracellular measurements. Organic and Biomolecular Chemistry, 2015, 13, (28), 7736-7749.

[14] Chen, L.; Wu, J.; Schmuck, C.; Tian, H., A switchable peptide sensor for real-time lysosomal tracking. Chemical Communications, 2014, 50, (49), 6443-6446.

[15] Heinrichs, G.; Schellenträger, M.; Kubik, S., An Enantioselective Fluorescence Sensor for Glucose Based on a Cyclic Tetrapeptide Containing Two Boronic Acid Binding Sites. European Journal of Organic Chemistry, 2006, 2006, (18), 4177-4186.

[16] Burguete, M.I.; Galindo, F.; Luis, S.V.; Vigara, L., Ratiometric fluorescence sensing of phenylalanine derivatives by synthetic macrocyclic receptors. Journal of Photochemistry and Photobiology A: Chemistry, 2010, 209, (1), 61-67.

[17] Butler, S.J.; Jolliffe, K.A., Selective Pyrophosphate Recognition by Cyclic Peptide Receptors in Physiological Saline. Chemistry - An Asian Journal, 2012, 7, (11), 26212628.

[18] Liu, X.; Ngo, H.T.; Ge, Z.; Butler, S.J.; Jolliffe, K.A., Tuning colourimetric indicator displacement assays for naked-eye sensing of pyrophosphate in aqueous media. Chemical Science, 2013, 4, (4), 1680-1686.

[19] Liu, X.; Smith, D.G.; Jolliffe, K.A., Are two better than one? Comparing intermolecular and intramolecular indicator displacement assays in pyrophosphate sensors. Chemical Communications, 2016, 52, (54), 8463-8466.

[20] Oh, K.J.; Cash, K.J.; Plaxco, K.W., Excimer-Based Peptide Beacons: A Convenient Experimental Approach for Monitoring Polypeptide-Protein and Polypeptide-Oligonucleotide Interactions. Journal of the American Chemical Society, 2006, 128, (43), 14018-14019.
[21] Wu, J.; Zou, Y.; Li, C.; Sicking, W.; Piantanida, I.; Yi, T.; Schmuck, C., A Molecular Peptide Beacon for the Ratiometric Sensing of Nucleic Acids. Journal of the American Chemical Society, 2012, 134, (4), 1958-1961.

[22] Maity, D.; Jiang, J.; Ehlers, M.; Wu, J.; Schmuck, C., A FRET-enabled molecular peptide beacon with a significant red shift for the ratiometric detection of nucleic acids. Chemical Communications, 2016, 52, (36), 6134-6137.

[23] Maity, D.; Schmuck, C., Fluorescent Peptide Beacons for the Selective Ratiometric Detection of Heparin. Chemistry - A European Journal, 2016, 22, (37), 1315613161.

[24] Maity, D.; Li, M.; Ehlers, M.; Schmuck, C., A metalfree fluorescence turn-on molecular probe for detection of nucleoside triphosphates. Chemical Communications, 2017, 53, (1), 208-211.

[25] Alfonso, I.; Quesada, R., Biological activity of synthetic ionophores: ion transporters as prospective drugs? Chemical Science, 2013, 4, (8), 3009-3019.

[26] Hurdle, J.G.; O’Neill, A.J.; Chopra, I.; Lee, R.E., Targeting bacterial membrane function: an underexploited mechanism for treating persistent infections. Nature reviews. Microbiology, 2011, 9, (1), 62.

[27] Ashcroft, F.M., From molecule to malady. Nature, 2006, 440, (7083), 440.

[28] Gentilucci, L.; Tolomelli, A.; Squassabia, F., Peptides and peptidomimetics in medicine, surgery and biotechnology. Current medicinal chemistry, 2006, 13, (20), 2449-2466.

[29] Sarabia, F.; Chammaa, S.; Ruiz, A.S.; Ortiz, L.M.; Herrera, F.L., Chemistry and biology of cyclic depsipeptides of medicinal and biological interest. Current medicinal chemistry, 2004, 11, (10), 1309-1332.

[30] Ohnishi, M.; Urry, D., Solution conformation of valinomycin-potassium ion complex. Science, 1970, 168, (3935), 1091-1092.

[31] Duax, W.; Hauptman, H.; Weeks, C.; Norton, D., Valinomycin crystal structure determination by direct methods. Science, 1972, 176, (4037), 911-914.

[32] Pinkerton, M.; Steinrauf, L.; Dawkins, P., The molecular structure and some transport properties of valinomycin. Biochemical and biophysical research communications, 1969, 35, (4), 512-518.

[33] Fernandez-Lopez, S.; Hui-Sun, K.; Choi, E.C.; Delgado, M., Antibacterial agents based on the cyclic D, Lalpha-peptide architecture. Nature, 2001, 412, (6845), 452.

[34] Ghadiri, M.R.; Granja, J.R.; Milligan, R.A.; McRee, D.E.; Khazanovich, N., Self-assembling organic nanotubes based on a cyclic peptide architecture. Nature, 1993, 366, (6453), 324.

[35] Ghadiri, M.R.; Granja, J.R.; Buehler, L.K., Artificial transmembrane ion channels from self-assembling peptide nanotubes. Nature, 1994, 369, (6478), 301-304.

[36] Dartois, V.; Sanchez-Quesada, J.; Cabezas, E.; Chi, E.; Dubbelde, C.; Dunn, C.; Granja, J.; Gritzen, C.; Weinberger, D.; Ghadiri, M.R., Systemic antibacterial activity of novel synthetic cyclic peptides. Antimicrobial agents and chemotherapy, 2005, 49, (8), 3302-3310. 
[37] Motiei, L.; Rahimipour, S.; Thayer, D.A.; Wong, C.H.; Ghadiri, M.R., Antibacterial cyclic d, 1- $\alpha$-glycopeptides. Chemical Communications, 2009, (25), 3693-3695.

[38] Danial, M.; Tran, C.M.-N.; Young, P.G.; Perrier, S.; Jolliffe, K.A., Janus cyclic peptide-polymer nanotubes. Nature communications, 2013, 4, 2780.

[39] Danial, M.; Tran, C.M.-N.; Jolliffe, K.A.; Perrier, S., Thermal gating in lipid membranes using thermoresponsive cyclic peptide-polymer conjugates. Journal of the American Chemical Society, 2014, 136, (22), 8018-8026.

[40] Clark, T.D.; Buehler, L.K.; Ghadiri, M.R., Selfassembling cyclic $\beta 3$-peptide nanotubes as artificial transmembrane ion channels. Journal of the American Chemical Society, 1998, 120, (4), 651-656.

[41] Brea, R.J.; Reiriz, C.; Granja, J.R., Towards functional bionanomaterials based on self-assembling cyclic peptide nanotubes. Chemical Society Reviews, 2010, 39, (5), 1448-1456.

[42] Montenegro, J.; Ghadiri, M.R.; Granja, J.R., Ion channel models based on self-assembling cyclic peptide nanotubes. Accounts of chemical research, 2013, 46, (12), 2955-2965.

[43] Rodríguez-Vázquez, N.; Lionel Ozores, H.; Guerra, A.; González-Freire, E.; Fuertes, A.; Panciera, M.; M Priegue, J.; Outeiral, J.; Montenegro, J.; García-Fandiño, R., Membrane-targeted self-assembling cyclic peptide nanotubes. Current topics in medicinal chemistry, 2014, 14, (23), 2647 2661.

[44] García-Fandiño, R.; Amorín, M.; Castedo, L.; Granja, J.R., Transmembrane ion transport by self-assembling $\alpha, \gamma$-peptide nanotubes. Chemical Science, 2012, 3, (11), 3280-3285.

[45] Rodríguez-Vázquez, N.; Amorín, M.; Granja, J.R., Recent advances in controlling the internal and external properties of self-assembling cyclic peptide nanotubes and dimers. Organic \& Biomolecular Chemistry, 2017, 15, (21), 4490-4505.

[46] Rodríguez-Vázquez, N.; García-Fandiño, R.; Amorín, M.; Granja, J.R., Self-assembling $\alpha, \gamma$-cyclic peptides that generate cavities with tunable properties. Chemical Science, 2016, 7, (1), 183-187.

[47] Rodríguez-Vázquez, N.; García-Fandiño, R.; Aldegunde, M.J.; Brea, J.; Loza, M.I.; Amorín, M.; Granja, J.R., cis-Platinum Complex Encapsulated in Self-Assembling Cyclic Peptide Dimers. Organic Letters, 2017.

[48] Rodríguez-Vázquez, N.; Amorín, M.; Alfonso, I.; Granja, J.R., Anion Recognition and Induced Self-Assembly of an $\alpha, \gamma$-Cyclic Peptide To Form Spherical Clusters. Angewandte Chemie International Edition, 2016, 55, (14), 4504-4508.

[49] Łowicki, D.; Huczyński, A.; Stefańska, J.; Brzezinski, B., Spectroscopic, semi-empirical and antimicrobial studies of a new amide of monensin A with 4aminobenzo-15-crown-5 and its complexes with $\mathrm{Na}+$ cation at 1: 1 and 1: 2 ratios. Tetrahedron, 2011, 67, (7), 1468-1478. [50] Boudreault, P.-L.; Voyer, N., Synthesis, characterization and cytolytic activity of $\alpha$-helical amphiphilic peptide nanostructures containing crown ethers. Organic \& biomolecular chemistry, 2007, 5, (9), 1459-1465.
[51] Otis, F.o.; Racine-Berthiaume, C.; Voyer, N., How far can a sodium ion travel within a lipid bilayer? Journal of the American Chemical Society, 2011, 133, (17), 6481-6483.

[52] Biron, E.; Otis, F.; Meillon, J.-C.; Robitaille, M.; Lamothe, J.; Van Hove, P.; Cormier, M.-E.; Voyer, N., Design, synthesis, and characterization of peptide nanostructures having ion channel activity. Bioorganic \& medicinal chemistry, 2004, 12, (6), 1279-1290.

[53] Vandenburg, Y.R.; Smith, B.D.; Biron, E.; Voyer, N., Membrane disruption ability of facially amphiphilic helical peptides. Chemical Communications, 2002, (16), 1694-1695.

[54] Boudreault, P.-L.; Arseneault, M.; Otis, F.; Voyer, N., Nanoscale tools to selectively destroy cancer cells. Chemical Communications, 2008, (18), 2118-2120.

[55] Xin, P.; Zhu, P.; Su, P.; Hou, J.-L.; Li, Z.-T., Hydrogen-bonded helical hydrazide oligomers and polymer that mimic the ion transport of gramicidin A. Journal of the American Chemical Society, 2014, 136, (38), 13078-13081.

[56] Zhang, D.-W.; Zhao, X.; Hou, J.-L.; Li, Z.-T., Aromatic amide foldamers: structures, properties, and functions. Chemical reviews, 2012, 112, (10), 5271-5316.

[57] Si, W.; Xin, P.; Li, Z.-T.; Hou, J.-L., Tubular unimolecular transmembrane channels: construction strategy and transport activities. Accounts of chemical research, 2015, 48, (6), 1612-1619.

[58] Chen, L.; Si, W.; Zhang, L.; Tang, G.; Li, Z.-T.; Hou, J.-L., Chiral selective transmembrane transport of amino acids through artificial channels. Journal of the American Chemical Society, 2013, 135, (6), 2152-2155.

[59] Si, W.; Li, Z.T.; Hou, J.L., Voltage-driven reversible insertion into and leaving from a lipid bilayer: Tuning transmembrane transport of artificial channels. Angewandte Chemie International Edition, 2014, 53, (18), 4578-4581.

[60] Zhang, M.; Zhu, P.-P.; Xin, P.; Si, W.; Li, Z.-T.; Hou, J.-L., Synthetic Channel Specifically Inserts into the Lipid Bilayer of Gram-Positive Bacteria but not that of Mammalian Erythrocytes. Angewandte Chemie International Edition, 2017, 56, (11), 2999-3003.

[61] Oblatt-Montal, M.; Reddy, G.L.; Iwamoto, T.; Tomich, J.M.; Montal, M., Identification of an ion channelforming motif in the primary structure of CFTR, the cystic fibrosis chloride channel. Proceedings of the National Academy of Sciences of the United States of America, 1994, 91, (4), 1495-1499.

[62] Wallace, D.P.; Tomich, J.M.; Eppler, J.W.; Iwamoto, T.; Grantham, J.J.; Sullivan, L.P., A synthetic channelforming peptide induces $\mathrm{Cl}-$ secretion: modulation by $\mathrm{Ca} 2+-$ dependent $\mathrm{K}+$ channels. Biochimica et Biophysica Acta (BBA)-Biomembranes, 2000, 1464, (1), 69-82.

[63] Gao, L.; Broughman, J.R.; Iwamoto, T.; Tomich, J.M.; Venglarik, C.J.; Forman, H.J., Synthetic chloride channel restores glutathione secretion in cystic fibrosis airway epithelia. American Journal of Physiology-Lung Cellular and Molecular Physiology, 2001, 281, (1), L24-L30.

[64] Wencewicz, T.A.; Möllmann, U.; Long, T.E.; Miller, M.J., Is drug release necessary for antimicrobial activity of siderophore-drug conjugates? Syntheses and biological studies of the naturally occurring salmycin "Trojan Horse" 
antibiotics and synthetic desferridanoxamine-antibiotic conjugates. BioMetals, 2009, 22, (4), 633.

[65] Broughman, J.R.; Brandt, R.M.; Hastings, C.; Iwamoto, T.; Tomich, J.M.; Schultz, B.D., Channel-forming peptide modulates transepithelial electrical conductance and solute permeability. American Journal of Physiology-Cell Physiology, 2004, 286, (6), C1312-C1323.

[66] Martin, J.; Malreddy, P.; Iwamoto, T.; Freeman, L.C.; Davidson, H.J.; Tomich, J.M.; Schultz, B.D., NC-1059: A Channel-Forming Peptide That Modulates Drug Delivery across In Vitro Corneal Epithelium. Investigative Ophthalmology \& Visual Science, 2009, 50, (7), 3337-3345.

[67] Gokel, G.W.; Barkey, N., Transport of chloride ion through phospholipid bilayers mediated by synthetic ionophores. New Journal of Chemistry, 2009, 33, (5), 947963.

[68] Gokel, G.W.; Negin, S., Synthetic membrane active amphiphiles. Advanced drug delivery reviews, 2012, 64, (9), 784-796.

[69] Pajewski, R.; Garcia-Medina, R.; Brody, S.L.; Leevy, W.M.; Schlesinger, P.H.; Gokel, G.W., A synthetic, chloride-selective channel that alters chloride transport in epithelial cells. Chemical Communications, 2006, (3), 329331.

[70] Li, X.; Shen, B.; Yao, X.-Q.; Yang, D., A small synthetic molecule forms chloride channels to mediate chloride transport across cell membranes. Journal of the American Chemical Society, 2007, 129, (23), 7264-7265.

[71] Li, X.; Shen, B.; Yao, X.-Q.; Yang, D., Synthetic chloride channel regulates cell membrane potentials and voltage-gated calcium channels. Journal of the American Chemical Society, 2009, 131, (38), 13676-13680.

[72] Shen, B.; Li, X.; Wang, F.; Yao, X.; Yang, D., A synthetic chloride channel restores chloride conductance in human cystic fibrosis epithelial cells. PLoS One, 2012, 7, (4), e34694.

[73] Liu, P.-Y.; Li, S.-T.; Shen, F.-F.; Ko, W.-H.; Yao, X.-Q.; Yang, D., A small synthetic molecule functions as a chloride-bicarbonate dual-transporter and induces chloride secretion in cells. Chemical Communications, 2016, 52, (46), 7380-7383.

[74] Martí, I.; Rubio, J.; Bolte, M.; Burguete, M.I.; Vicent, C.; Quesada, R.; Alfonso, I.; Luis, S.V., Tuning chloride binding, encapsulation, and transport by peripheral substitution of pseudopeptidic tripodal small cages. Chemistry - A European Journal, 2012, 18, (52), 16728-16741.

[75] Martí, I.; Bolte, M.; Burguete, M.I.; Vicent, C.; Alfonso, I.; Luis, S.V., Tight and selective caging of chloride ions by a pseudopeptidic host. Chemistry - A European Journal, 2014, 20, (24), 7458-7464.

[76] Martí, I.; Burguete, M.I.; Gale, P.A.; Luis, S.V., Acyclic Pseudopeptidic Hosts as Molecular Receptors and Transporters for Anions. European Journal of Organic Chemistry, 2015, 2015, (23), 5150-5158.

[77] Gaetke, L.M.; Chow, C.K., Copper toxicity, oxidative stress, and antioxidant nutrients. Toxicology, 2003, 189, (1), 147-163.

[78] Ala, A.; Walker, A.P.; Ashkan, K.; Dooley, J.S.; Schilsky, M.L., Wilson's disease. The Lancet, 2007, 369, (9559), 397-408.
[79] Gaggelli, E.; Kozlowski, H.; Valensin, D.; Valensin, G., Copper homeostasis and neurodegenerative disorders (Alzheimer's, prion, and Parkinson's diseases and amyotrophic lateral sclerosis). Chemical reviews, 2006, 106, (6), 1995-2044.

[80] Nose, Y.; Rees, E.M.; Thiele, D.J., Structure of the Ctr1 copper trans'PORE'ter reveals novel architecture. Trends Biochem Sci, 2006, 31, (11), 604-607.

[81] Pujol, A.M.; Gateau, C.; Lebrun, C.; Delangle, P., A Cysteine-Based Tripodal Chelator with a High Affinity and Selectivity for Copper(I). Journal of the American Chemical Society, 2009, 131, (20), 6928-6929.

[82] Pujol, A.M.; Cuillel, M.; Renaudet, O.; Lebrun, C.; Charbonnier, P.; Cassio, D.; Gateau, C.; Dumy, P.; Mintz, E.; Delangle, P., Hepatocyte Targeting and Intracellular Copper Chelation by a Thiol-Containing Glycocyclopeptide. Journal of the American Chemical Society, 2011, 133, (2), 286-296.

[83] Pujol, A.M.; Cuillel, M.; Jullien, A.-S.; Lebrun, C.; Cassio, D.; Mintz, E.; Gateau, C.; Delangle, P., A Sulfur Tripod Glycoconjugate that Releases a High-Affinity Copper Chelator in Hepatocytes. Angewandte Chemie International Edition, 2012, 51, (30), 7445-7448.

[84] Blasco, S.; Burguete, M.I.; Clares, M.P.; GarcíaEspaña, E.; Escorihuela, J.; Luis, S.V., Coordination of $\mathrm{Cu} 2+$ Ions to C2 Symmetric Pseudopeptides Derived from Valine. Inorganic Chemistry, 2010, 49, (17), 7841-7852.

[85] Faggi, E.; Gavara, R.; Bolte, M.; Fajarí, L.; Juliá, L.; Rodríguez, L.; Alfonso, I., Copper(ii) complexes of macrocyclic and open-chain pseudopeptidic ligands: synthesis, characterization and interaction with dicarboxylates. Dalton Transactions, 2015, 44, (28), 1270012710.

[86] Kubik, S.; Goddard, R.; Kirchner, R.; Nolting, D.; Seidel, J., A Cyclic Hexapeptide Containing L-Proline and 6Aminopicolinic Acid Subunits Binds Anions in Water. Angewandte Chemie International Edition, 2001, 40, (14), 2648-2651.

[87] Kubik, S.; Kirchner, R.; Nolting, D.; Seidel, J., A Molecular Oyster: A Neutral Anion Receptor Containing Two Cyclopeptide Subunits with a Remarkable Sulfate Affinity in Aqueous Solution. Journal of the American Chemical Society, 2002, 124, (43), 12752-12760.

[88] Fiehn, T.; Goddard, R.; Seidel, R.W.; Kubik, S., A Cyclopeptide-Derived Molecular Cage for Sulfate Ions That Closes with a Click. Chemistry - A European Journal, 2010, 16, (24), 7241-7255.

[89] Schaly, A.; Belda, R.; García-España, E.; Kubik, S., Selective Recognition of Sulfate Anions by a CyclopeptideDerived Receptor in Aqueous Phosphate Buffer. Organic Letters, 2013, 15, (24), 6238-6241.

[90] Elmes, R.B.P.; Jolliffe, K.A., Anion recognition by cyclic peptides. Chemical Communications, 2015, 51, (24), 4951-4968.

[91] Alfonso, I.; Burguete, M.I.; Galindo, F.; Luis, S.V.; Vigara, L., Unraveling the Molecular Recognition of Amino Acid Derivatives by a Pseudopeptidic Macrocycle: ESI-MS, NMR, Fluorescence, and Modeling Studies. The Journal of Organic Chemistry, 2009, 74, (16), 6130-6142.

[92] Alfonso, I.; Bolte, M.; Bru, M.; Burguete, M.I.; Luis, S.V.; Vicent, C., Molecular recognition of N-protected 
dipeptides by pseudopeptidic macrocycles: A comparative study of the supramolecular complexes by ESI-MS and NMR. Organic and Biomolecular Chemistry, 2010, 8, (6), 13291339.

[93] Faggi, E.; Moure, A.; Bolte, M.; Vicent, C.; Luis, S.V.; Alfonso, I., Pseudopeptidic cages as receptors for Nprotected dipeptides. Journal of Organic Chemistry, 2014, 79, (10), 4590-4601.

[94] Faggi, E.; Vicent, C.; Luis, S.V.; Alfonso, I., Stereoselective recognition of the Ac-Glu-Tyr-OH dipeptide by pseudopeptidic cages. Organic and Biomolecular Chemistry, 2015, 13, (48), 11721-11731.

[95] Williams, D.M.; Wang, D.; Cole, P.A., Chemical rescue of a mutant protein-tyrosine kinase. J Biol Chem, 2000, 275, (49), 38127-38130.

[96] Casaletto, J.B.; McClatchey, A.I., Spatial regulation of receptor tyrosine kinases in development and cancer. Nat Rev Cancer, 2012, 12, (6), 387-400.

[97] Ma, J.; Jiang, T.; Tan, L.; Yu, J.-T., TYROBP in Alzheimer's Disease. Molecular Neurobiology, 2015, 51, (2), 820-826.

[98] Faggi, E.; Pérez, Y.; Luis, S.V.; Alfonso, I., Supramolecular protection from the enzymatic tyrosine phosphorylation in a polypeptide. Chemical Communications, 2016, 52, (52), 8142-8145.

[99] Kalafatovic, D.; Nobis, M.; Javid, N.; Frederix, P.W.J.M.; Anderson, K.I.; Saunders, B.R.; Ulijn, R.V., MMP9 triggered micelle-to-fibre transitions for slow release of doxorubicin. Biomaterials Science, 2015, 3, (2), 246-249.

[100] Kuchelmeister, H.Y.; Gutschmidt, A.; Tillmann, S.; Knauer, S.; Schmuck, C., Efficient gene delivery into cells by a surprisingly small three-armed peptide ligand. Chemical Science, 2012, 3, (4), 996-1002.

[101] Li, M.; Schlesiger, S.; Knauer, S.K.; Schmuck, C., A Tailor-Made Specific Anion-Binding Motif in the Side Chain Transforms a Tetrapeptide into an Efficient Vector for Gene Delivery. Angewandte Chemie International Edition, 2015, 54, (10), 2941-2944.

[102] Li, M.; Ehlers, M.; Schlesiger, S.; Zellermann, E.; Knauer, S.K.; Schmuck, C., Incorporation of a Non-Natural Arginine Analogue into a Cyclic Peptide Leads to Formation of Positively Charged Nanofibers Capable of Gene Transfection. Angewandte Chemie International Edition, 2016, 55, (2), 598-601.

[103] Lei, E.K.; Pereira, M.P.; Kelley, S.O., Tuning the Intracellular Bacterial Targeting of Peptidic Vectors. Angewandte Chemie International Edition, 2013, 52, (37), 9660-9663. 